\title{
Thin film lubrication in the past 20 years
}

\author{
Liran MA, Jianbin LUO* \\ State Key Laboratory of Tribology, Tsinghua University, Beijing 100084, China \\ Received: 17 August 2016 / Revised: 25 November 2016 / Accepted: 29 November 2016 \\ (C) The author(s) 2016. This article is published with open access at Springerlink.com
}

\begin{abstract}
Thin film lubrication (TFL), a lubrication regime that fills the gap between boundary lubrication (BL) and elastohydrodynamic lubrication (EHL) regimes, was proposed 20 years ago. Since it was first recorded in the literature, TFL has gained substantial interest and has been advanced in the fields of theoretical and experimental research. Following the revelation of the TFL phenomenon and its central ideas, many studies have been conducted. This paper attempts to systematically review the major developments in terms of both the history and the advances in TFL. It begins with the description and definition of TFL, followed by the state-of-art studies on experimental technologies and their applications. Future prospects of relevant studies and applications are also discussed.
\end{abstract}

Keywords: thin film lubrication; TFL; thin EHL film; ordered structure; interface

\section{Introduction}

Numerous attempts have been made and documented to illuminate the lubrication mechanism, such as the revelation of the elastohydrodynamic lubrication (EHL) regime [1,2] and boundary lubrication (BL) regime [3]. In the EHL regime, the film thickness is dominated by elastohydrodynamic factors, i.e., the rolling speed, contact pressure, viscosity of lubricant etc., while in the $\mathrm{BL}$ regime, the properties of the lubricant films are dominated by chemical action between substrate surfaces and lubricant molecules. Since its discovery in 1994, thin film lubrication (TFL) [4, 5] has generated a lot of interest in both theoretical and experimental areas due to the unprecedented significance of bridging the gap between the EHL and BL regimes. The lubrication state in TFL regime has been indicated to be related to both physical factors and chemical factors of solid surfaces and molecules of liquid lubricants $[4,5]$.

In the past several decades, insight into the nature of lubrication has emerged through understanding

* Corresponding author: Jianbin LUO.

E-mail: luojb@tsinghua.edu.cn the behavior of the thin films between two rubbing surfaces. Interests of researchers have often focused on the main modes of lubrication in terms of fluidic and boundary processes. The basis of fluid lubrication can be traced back to 1886, as reported by Reynolds [6]. Elastohydrodynamic lubrication is considered to be of great significance in the history of lubrication, the concept of which was first proposed by Grubin in 1949, followed by extensive and systematical studies since the 1950s by Dowson and Higginson $(1959,1966)$ [7], Cheng (1970) [8], Hamrock and Dowson (1981) [9], Zhu et al. [10,11], and so on. Boundary lubrication, involving the wear-reducing lubricant layers adsorbed on the rubbing surfaces, was first proposed by Hardy in the 1920s [12]. Then, the model was successively improved upon by many tribologists, such as Bowdeon and Tabor [13], Adamson [14], Kingsbury [15], Cameron [16], and Israelachvili [17], suggesting that in boundary lubrication, the load is normally carried by the highly tenacious layers at the nanometer scale on the surface rather than the fluid film, which is more than tens of nanometers thick, as in the EHL regime. Thus, it was concluded that a gap exists between the EHL and boundary lubrication.

A remarkable lubrication regime that solves the 
transition from boundary lubrication to EHL has been revealed, termed thin film lubrication (TFL) [4, 5], which has been systematically investigated since the 1990s by a number of researchers, such as Johnston et al. [18], Luo et al. [19-22], Tichy [23, 24], Hartal et al. [25], Matsuoka and Kato [26], Gao and Spikes [27] and so on. Luo and Yian [28] suggested a gap-bridging model by describing the interlaced change of qualitative lubrication and quantitative parameters in 1989, which can be considered to be the embryo of the thin film lubrication model. The super thin film lubrication was proposed and developed by Spikes et al. [18], and it described the situation with lubricating films less than $15 \mathrm{~nm}$. Gupta et al. [29] succeeded with revealing the microscopic behavior of lubricant films ranging from 1 to $10 \mathrm{~nm}$ by examining various contributions to the disjoining pressure. Both the van der Waals force and the structural force resulting from the molecular orientation and packing have been emphasized. In 1994, the physical model of thin film lubrication (TFL) was respectively proposed by Luo and Wen [4,5], indicating that the combined effect of molecules attached on surfaces and in the thin lubricating film resulted in a distinct lubrication performance. From that time forth, growing interest has been stimulated to reveal the origins and characteristics of thin film lubrication models, bringing numerous advances to both experimental $[23,24,30,31]$ and theoretical studies, as Hu et al. [33-35] reported.

\section{Definition of thin film lubrication and lubrication map}

\subsection{Definition of thin film lubrication}

The distinctive properties of thin film lubrication were calling for an accurate definition of this independent lubrication regime. The TFL model, shown in Fig. 1, which was proposed by Luo et al. [4, 5] indicates that in the thin film lubrication regime, while the gap size is in the range of several nanometers to tens of nanometers, the lubricant film will be dominated by molecular behavior in different micro/nano regions, substantially involving three layers, i.e., the adsorbed layer indicated to be a monomolecular layer where molecules absorbed and packed on the solid surface, the dynamic fluid layer, which is in the center of the gap, and the ordered layer, which is between the absorbed layer and the fluid layer, coming into being during the shear process as the transition region. Lubrication in such a layer can be defined as thin film lubrication (TFL) $[4,5,19,20]$, where the film thickness remains dependent on surface speed but the dependence deviates from the prediction of classical theory of EHL. The variation of the thickness ratio of these three kinds of layers will dominate the transition of lubrication regimes between the two solid surfaces. If the solid surfaces are far apart from each other, the fluid layer will become thick enough and the tribopair will act under hydrodynamic effects in terms of speed, pressure, and lubricant viscosity, but remain highly fluid in the EHL regime. If the two solid surfaces are so close to each other, i.e., the lubricant film becomes very thin or few nanometers thick with regard to the absorbed layer, the molecules are well ordered and firmly attached on the solid surfaces, resulting in a solid-like layer. Thus, a boundary lubrication regime will appear and it will be independent of the lubricant viscosity, speed, and so on. If the gap between two solid surfaces is a few of nanometers to tens of nanometers, the presence of a surface force induces the formation of not only the absorbed film, but also the ordered film, in which the molecules are not as ordered as the absorbed layer. The film thickness and tribological properties in the TFL regime are different from those in both the EHL and boundary lubrication (a)

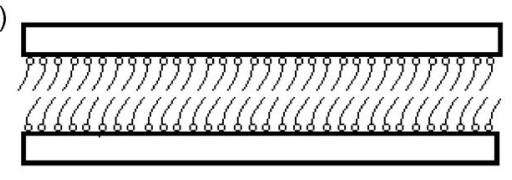

Hardy model (b)

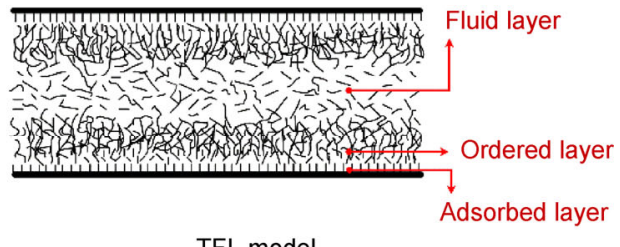

TFL model

Fig. 1 Basic model of TFL [4, 5]. Copyright 1996, Elsevier. 
regimes, and they are affected by a number of factors, such as the hydrodynamic effect, the molecular size, and the molecular polarization. The lubrication in the TFL regime has been regarded as the transition between the EHL and boundary lubrication, finely filling an unknown gap.

\subsection{Lubrication map}

It has been recognized that the lubrication between solid surfaces will be dominated by different regimes under different conditions, mainly involving hydrodynamic lubrication (HDL), elastohydrodynamic lubrication (EHL), thin film lubrication (TFL), and boundary lubrication (BL). The lubrication map shown in Fig. 2 [36] is obtained by using the ratio $h / R_{\mathrm{a}}$ (or $h / \sigma)$ to describe the lubrication regime, where $h$ is the lubricating film thickness and $R_{\mathrm{a}}$ (or $\sigma$ ) is the combined surface roughness of the two surfaces.

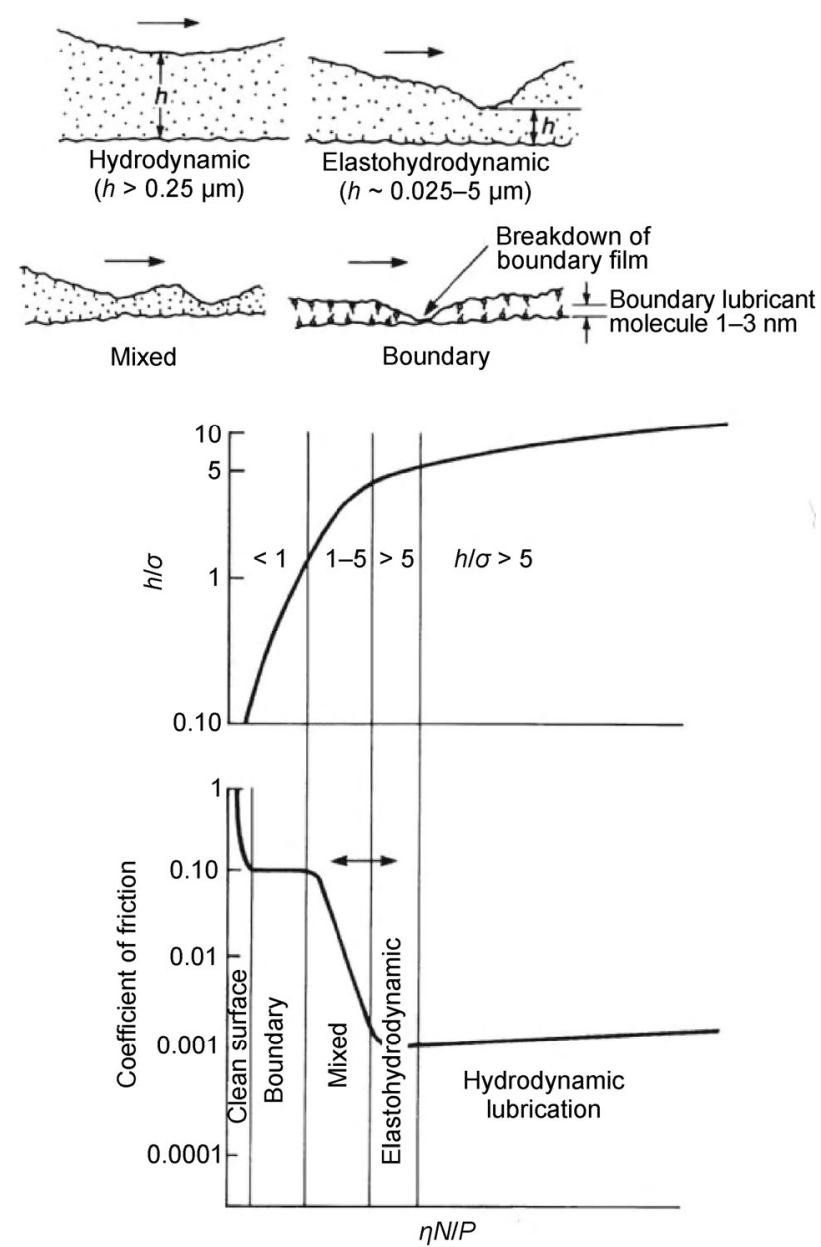

Fig. 2 Lubrication map defined by using only $h / R_{\mathrm{a}}$ (or $\left.h / \sigma\right)$ [36]. Copyright 2013, John Wiley and Sons.
Unfortunately, such a method cannot be used to describe the lubrication regime when the solid surfaces are quite smooth. According to the Hardy boundary lubrication model shown in Fig. 1, supposing that $R_{\mathrm{a}}$ is $0.1 \mathrm{~nm}$, the lubricating film thickness is $5 \mathrm{~nm}$, consisting of only two layers of molecules in between the two surfaces, a ratio $h / R_{\mathrm{a}}$ of 50 can be obtained. Based on the lubrication map in Fig. 2, the lubrication regime should be assigned to hydrodynamic lubrication, instead of boundary lubrication.

A lubrication map is required to precisely describe and distinguish among different regimes in the contact area. An effective and comprehensive method has been proposed by Luo and Wen $[37,38]$ to facilitate such distinction by using the ratios $h / R_{\mathrm{a}}$ and $h / R_{\mathrm{g}}$ together [38], where $h$ is the lubricating film thickness, $R_{\mathrm{a}}$ is the combined surface roughness of the two surfaces in relative motion, and $R_{\mathrm{g}}$ is the effective radius of the lubricant molecules. This method involves not only the film thickness and surface roughness but also the molecular size, and it significantly enables the establishment of a precise and full map of lubrication, as shown in Fig. 3 [4].

With regard to both flat and rough contacted surfaces, when the ratio $h / R_{\mathrm{a}}$ is larger than 3 , the dominant regime is boundary lubrication, when $h / R_{\mathrm{g}}$ is smaller than 3, while the dominant regime is EHL or HDL when the ratio $h / R_{\mathrm{g}}$ is higher than 15 , and in between is the TFL regime. The mixed lubrication regime (ML) is supposed to exist when the ratio $h / R_{\mathrm{a}}$ is less than 3 , but different types vary with different $h / R_{\mathrm{g}}$ as shown in Fig. 3. In the process of lubrication, all the factors, such as the pressure, rolling speed, and the chemical properties of molecules in lubrication film, will affect the two ratios $h / R_{\mathrm{a}}$ and $h / R_{\mathrm{g}}$, and thus result in the transition between different lubrication regimes.

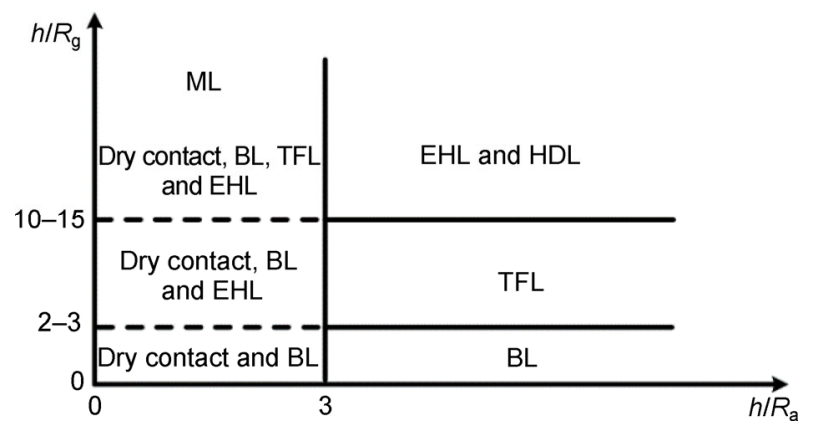

Fig. 3 Lubrication map proposed by Luo et al. [4]. 
Transitions between different lubrication regimes at the molecular level have been studied by both experimental and theoretical methods. The transition from ultra-thin lubrication to dry friction has been studied by Savio et al. [39] using molecular dynamics simulations. Hu et al. [40] studied how the film thickness response to the speed in the transition region between EHL and boundary lubrication. Those studies have strongly corroborated the assertion that the lubrication regime will be dominated by molecular behaviors when the lubricating film is relatively thin.

\section{Experimental techniques and facilities for the study of TFL}

The defining techniques allowing the study of TFL properties allow for the efficient detection of extremely thin lubrication films in a contact area, which have benefited from the development of modern technologies. In the past several decades, the prosperous nano science and technology has successfully enabled the exploration of the underlying basics and mechanism of lubrication [41,42]. Furthermore, the study of properties and mechanism at the molecular level of thin film lubrication has been significantly promoted.

\subsection{Methods based on the measurement of surface force: Surface force apparatus}

The surface force apparatus/balance (SFA/SFB), which was developed based on the technique of equal chromatic order (FECO) with $\mathrm{nN}$ force measurement resolution and sub nanometer gap size measurement resolution $[43,44]$, has been recognized to be highly efficient in precisely detecting both the acting force and separation between surfaces in relative motion. Since the introduction of SFA about four decades ago, many significant discoveries have been made [45-48]. With regard to the thin film lubrication, the ordered structure of molecules has been detected by using SFA/SFB between confined atomically smooth mica surfaces, as reported by Israelachvili et al. [43, 44], Klein $[49,50]$ and Granick et al. [51]. Surface forces are finally determined as a function of the separation of two back-silvered atomically smooth mica surfaces in crossed-cylinder geometry, as shown in Fig. 4 [49, 52]. Interference fringes can be obtained between the two

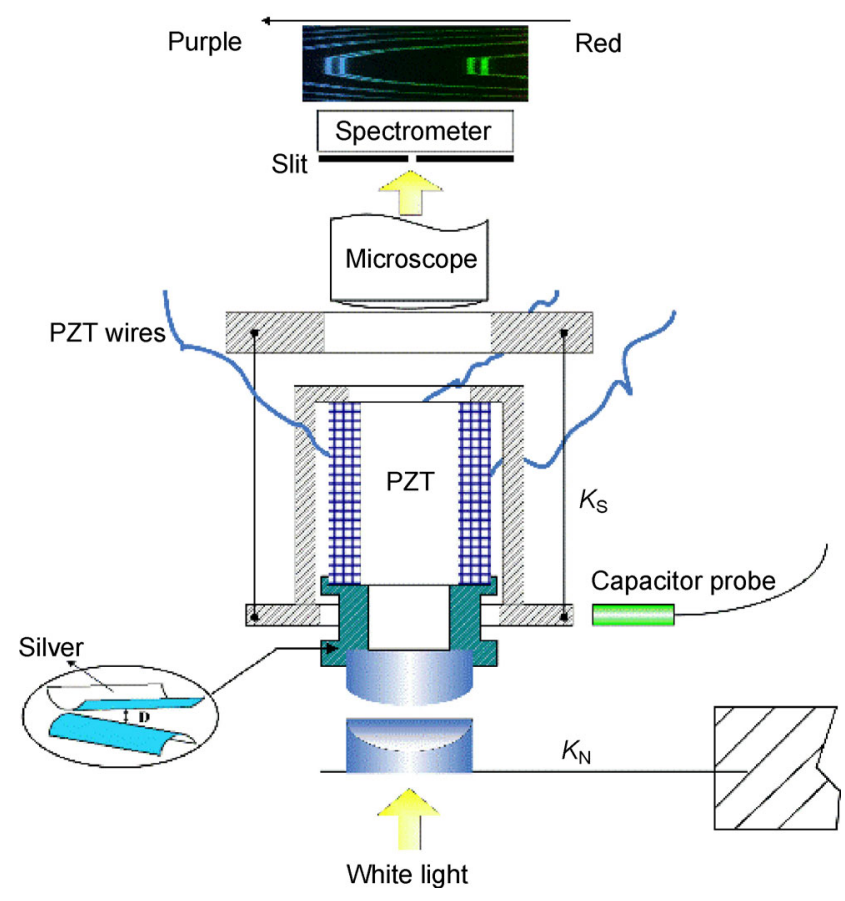

Fig. 4 Sketch of surface force balance developed by Klein et al. [49]. Copyright 1995, the American Association for the Advancement of Science.

sliver mirrors, with white light going through an optical multilayer. When the two surfaces across the lubrication media are brought into proximity, the tiny variation of the gap size can be obtained from interference fringes, resulting in a derivation of the interaction force between the two surfaces.

\subsection{Methods based on precision measurement of film thickness: Improved optical interference techniques}

As the mechanism of lubrication has been explored during the past several decades, film thickness measurement has occupied an important role. The most effective techniques for measuring the film thickness during the lubrication process have been recognized to be the ones developed based on the optical interference technique. The first application of an optical interference technique in a lubrication area can be traced back to 1966 [53], when the first graph of horseshoe constriction in EHL was constructed by Cameron and Gohar [53], with ball-on-disc geometry. Subsequently, based on this first application, the film thickness measurements were achieved by efforts made to improve the quality of the interference fringes 
[54, 55], while the idea of semi-reflective metallic layer yielded. However, the resolution of the film thickness measurement, strictly limited by diffraction limitation, could not be brought down to less than $100 \mathrm{~nm}$.

To break through the bottleneck, several improved techniques have been proposed during the past thirty years. These improvements have mainly focused on three approaches developed by tribologists from three groups. In 1988, the spacer layer interferometry was developed and proposed by Guanteng and Spikes [56], while a relative thick silica spacer layer was introduced to break through the resolution limitation, as shown in Fig. 5(a). The techniques of spacer layer interferometry and the improved one (by tracing the brightest interference fringe at varied wavelength taking advantages of a spectrometer) effectively enable the study of boundary and very thin film hydrodynamic lubrication [57-60]. Furthermore, the relative optical interference intensity (ROII) method was first proposed by Luo et al. in 1994 [4, 5], based on the subdivision of the interference image by the interference light intensity, as shown in Fig. 5(b). The technique of ROII has been proved to be able to provide a relatively high resolution of around $0.5 \mathrm{~nm}[4,5]$. The phenomenon of thin film lubrication was found based on the development of ROII technique, followed by the later improvement of this approach by Ma and Zhang [61].

(a)

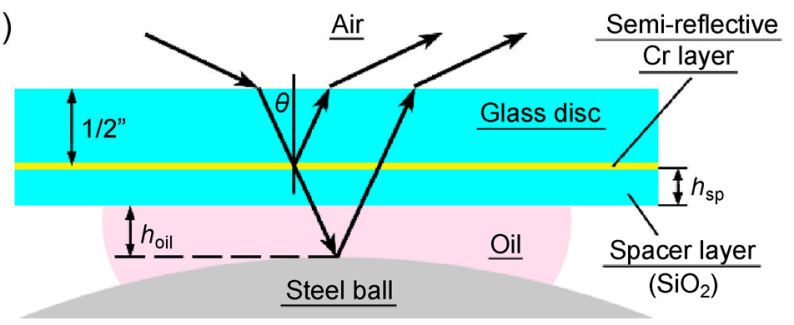

(b)

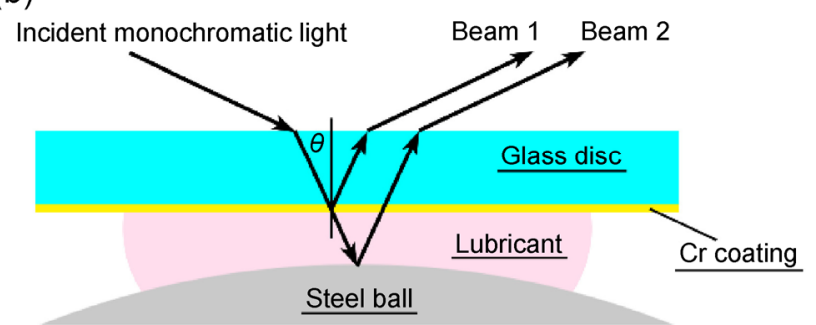

Fig. 5 Sketch of improved optical interference techniques; (a) space layer technique proposed by Guanteng and Spikes [60]. Copyright 2003, Plenum Publishing Corporation; (b) ROII technique proposed by Luo et al. [61]. Copyright 2009 Springer Science+ Business Media, LLC.
The ROII technique has allowed study of the basic properties of thin film lubrication, as well as the failure condition [62]. Based on the idea of division of the interference intensity, Guo and Wong $[63,64]$ developed the multiple-beam interference approach to measure the ultra-thin film thickness with a resolution of $1 \mathrm{~nm}$. In 1997, the colorimetric interferometry in EHL lubrication applications was developed by Hartl and his coworkers [65], combining conventional chromatic interferometry with differential colorimetry. The colorimetric interferometry technique, with a resolution of around $1 \mathrm{~nm}$, was reported to successfully capture the instantaneous EHD film thickness [66].

\subsection{Methods based on the in-situ detection of lubricant molecules: Molecular spectroscopy}

Modern insight into the nature of lubrication has emerged through understanding the molecular behaviors in nano-lubrication films, especially when the lubrication is in the boundary or thin film lubrication regime, where the molecular structure will play an important role on the lubrication performances. Molecular spectroscopy, including Raman spectroscopy, infrared spectroscopy and so on, is recognized to be quite efficient in achieving the in situ detection of lubricant molecular structures. The facilities constructed by introducing spectroscopy in the tribosystems have been demonstrated to be powerful enough to detect the ordering and orientation of lubricant molecules and the change in chemical bonds during the shearing process [52].

Using infrared spectra, Cann and Spikes $[67,68]$ have explored the chemical reaction and composition of lubricants during sliding, as shown in Fig. 6. By using such methods, lubricant structuring close to the metal surface has been found in thin lubrication films less than $100 \mathrm{~nm}$ [67]. Photoluminescence and absorption dichroism spectra were introduced into the surface force apparatus by Granick and his coworkers [69], enabling the quantification of the polymer chain alignment in confinement. The combination of X-ray diffraction and surface force apparatus were established by Golan et al. [70], providing the information in terms of shear-induced molecular orientation and structures nearby solid surfaces. Similar achievements on the detection of molecular orientation under shear effect 

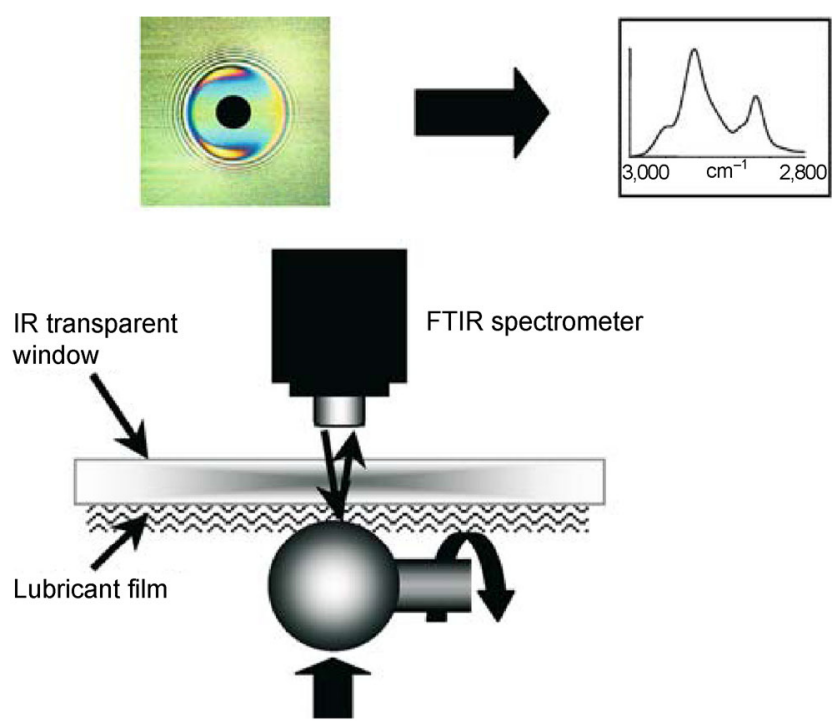

Fig. 6 Sketch for in-contact IR spectroscopy by Cann and Spikes [68]. Copyright 2005, Springer Science+Business Media, Inc.

have been made by Bae et al., using fluorescence spectra [71]. Raman spectroscopy is popular not only in chemistry, but also in tribology. Attempts have been made by several groups to introduce Raman spectra to the tribometer and SFA. Representatively, Bae et al. $[72,73]$ reported heterogeneous surface-induced structures of polydimethylsiloxane chains by combining Raman spectra with SFA. Furthermore, by introducing the polarization Raman spectra to the tribometer system, as shown in Fig. 7(a), Luo's group [74, 75] has successfully detected the molecular structure of both polar and nonpolar lubricant molecules in nano lubrication films, as shown in Fig. 7(b).
With regard to the thin film lubrication, the molecules in different layers are completely different. It is assumed that the molecules on the solid surfaces are structured and oriented, which calls for new techniques with better sensitivity to distinguish the molecules at solid/ liquid interfaces and in the bulk. Sum frequency generation spectroscopy [76,77], which has the advantage of only probing the very few molecules at interfaces, is one such techniques. Another technique is the surface enhanced Raman spectroscopy (SERS), which has been successfully used to investigate the molecules absorbed on the solid surfaces under both the effects of surface force and shear force by Gao et al. [78]. While using the SERS approach in lubrication systems, textured silver surfaces with nano structures were used as the contacted surfaces, resulting in a significant enhancement of the Raman signal, which was up to $10^{3}-10^{4}$ larger than the one on normal surfaces [78, 79], as shown in Fig. 8. These techniques will be very promising in revealing the lubrication mechanism at the molecular level and in future tribological studies.

\section{Basic properties of TFL and main influencing factors}

\subsection{Effect of rolling speed on TFL}

Similar to the situation in the EHL regime, film thickness has been found to be closely related to the speed of two surfaces in relative motion in the

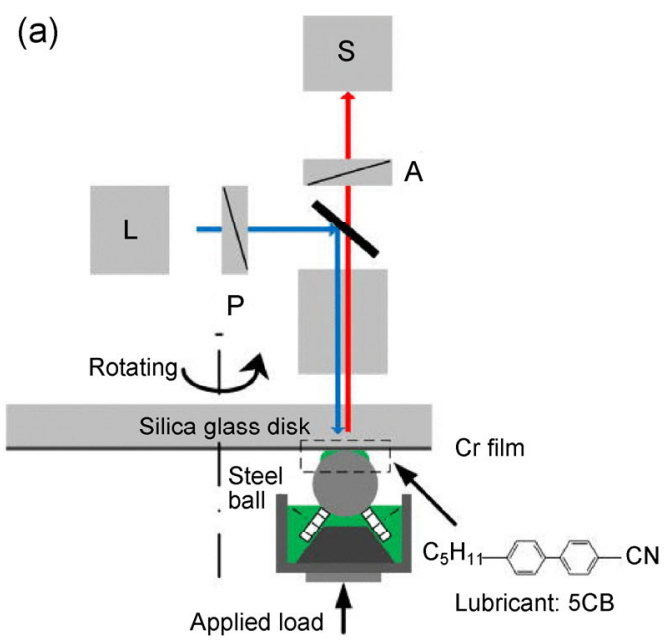

(b)

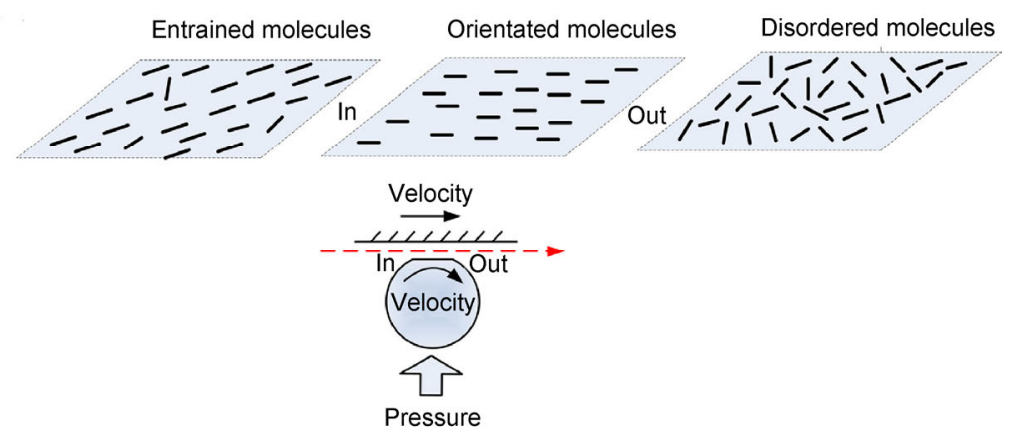

Fig. 7 (a) Schematic diagram of the in-situ experimental apparatus in Luo's group [74]. (b) The orientated liquid crystal molecules between two rubbing surfaces reported by Zhang et al. [74]. Copyright 2014, AIP Publishing LLC. 
TFL regime, as shown in Fig. 9 [4, 22]. However, the difference is that normally there is a critical point at the film formation curve in thin film lubrication regime, especially for the lubricant molecules with polar ends. The slope of the film formation curve changes obviously, indicating the significant transition from EHL to TFL $[4,22]$ during the variation of speed. It has been commonly recognized that the film formation in the EHL regime can be predicted by the Hamrock-Dowson equation [80], which exhibits a linear relationship with a slope of 0.67 between film thickness and the speed in dual-logarithm coordinates. However, film formation in the TFL regime is affected by the molecular interaction, which induces variation of the slope of film thickness dependence even in duallogarithmical coordinate. Luo et al. [4, 22] defined the slope of film thickness versus speed in dual-

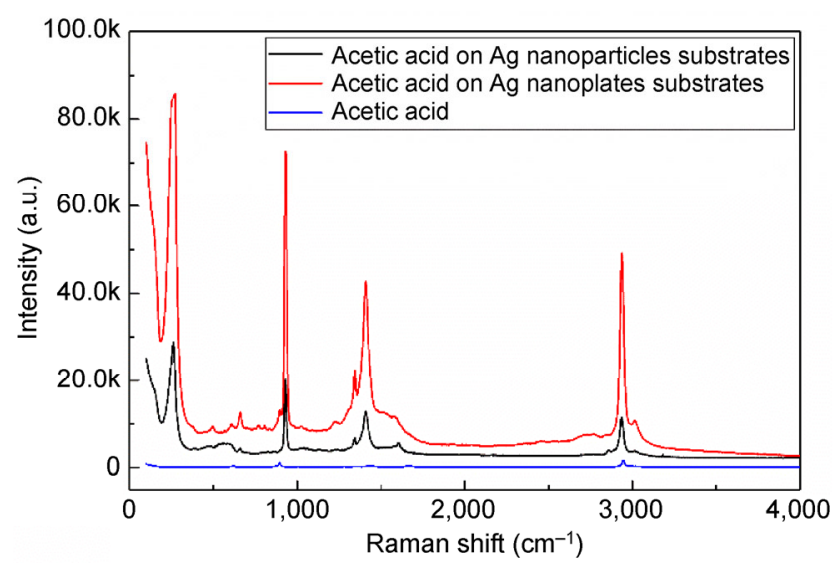

Fig. 8 Surface enhanced Raman technique by using silver substrates with nano structure reported by Gao et al. [78]. Copyright 2014, Royal Society of Chemistry.

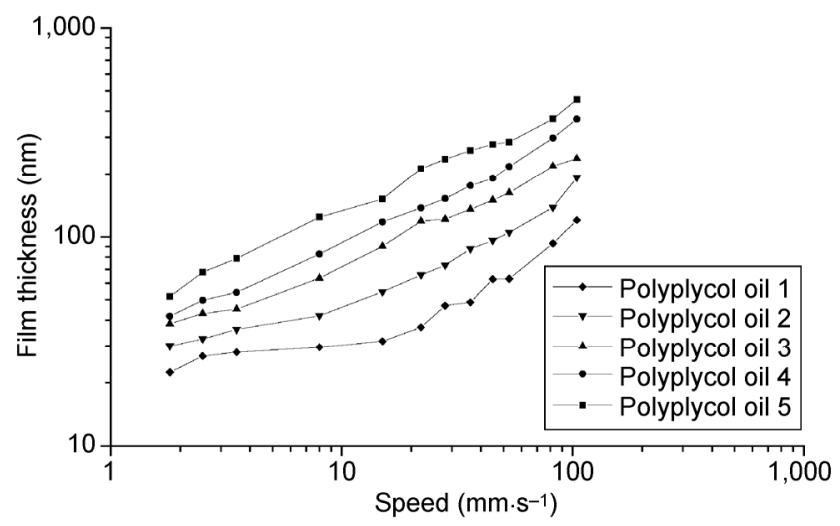

Fig. 9 Effect of viscosity on film formation performances of polyplycol oil (Pressure: $0.184 \mathrm{GPa}$, Temperature: $28^{\circ} \mathrm{C}$ ), reported by Luo et al. [4]. logarithmical coordinates as the speed index $\varphi[4,22]$, according to:

$$
h=k u^{\varphi}
$$

where $h$ is the central film thickness, $u$ is the rolling speed, $\varphi$ is the defined speed index, and $k$ is a constant relating to the lubricating conditions. They demonstrated a much low index value for the film thickness variation with speed in dual-logarithmical coordinate, while exploring the film formation characteristics of white oil 13604 trapped between a glass disc and a steel ball. In Fig. 9, as to the total film thickness involving both the static film (which results from the absorption of liquid molecules on the solid surfaces) and the dynamic film (which comes into being under a certain dynamic speeds), a speed index of 0.45 is obtained when the film thickness is above the critical point, which is still lower than that in EHL regime. Meanwhile, with regard to the dynamic fluid film, the speed index is found to be close to the one in the EHL regime. Thus, the existence of absorbed molecular layers on the solid surfaces, resulting in the static film, can be confirmed. The effect of the structured and absorbed layers on the solid surfaces will not totally emerge when the lubrication film is thick. Interestingly, the existence of the ordered film has been also concluded from the critical point of dynamic film $[4,5,22]$.

Other kinds of lubricants have been utilized to explain the film thickness response to the speed in the TFL regime, such as octamethylcyclotetrasiloxane (OMCTS) [31] and polymers (f-PAMA and OCP) [81], by different researchers. The deviation from linearity of the EHL prediction at low speed has been observed in double logarithmic coordinates in most cases.

It is of great significance to explore the film forming properties under extremely high speeds; unfortunately, this has been limited by the instrumentation in the past several decades. During the past few years, Luo's group has been working on studying the TFL properties under a rolling speed up to more than $40 \mathrm{~m} / \mathrm{s}$. Liang et al.'s work $[82,83]$ indicates that the film forming condition may transit into thin film lubrication (TFL) at extremely high speeds when it is under parched starvation, as shown in Fig. 10. The film thickness data were acquired on a self-designed 


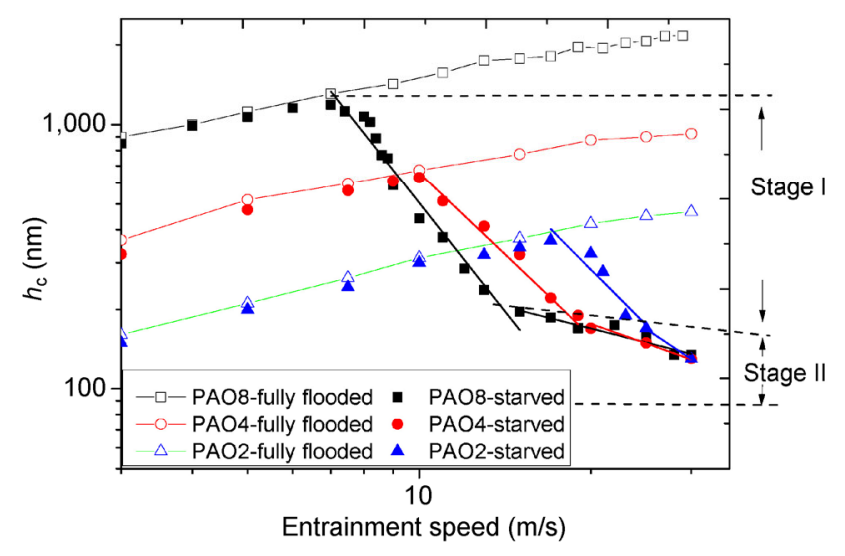

Fig. 10 Film formations of fully flooded and starved conditions at speed up to $30 \mathrm{~m} / \mathrm{s}$, measured by Liang et al. [82]. Copyright 2015, Elsevier Ltd.

ball on disc test rig up to $40 \mathrm{~m} / \mathrm{s}$ via the technique of relative optical interference intensity. The measured results show that the critical film thickness where the lubricant film collapses reduced. It is indicated that the high speed flow has the ability to drive lubricant molecules to rearrange themselves in the TFL and critical film thickness higher than $100 \mathrm{~nm}$ is achieved as the viscosity decreases. The film thickness of oil with higher viscosity decreases with speed or time more slowly and maintains a thicker film thickness, which is the opposite trend of EHL lubrication.

Thin film lubrication at high speeds shows some distinct features compared with the classical TFL behavior at lower speeds [82,83]. First of all, it is under parched starvation. Only in such condition, the film thickness will decrease to thin film lubrication regime, as the film thickness under fully flooded lubrication at high speeds can achieve hundreds of nanometers. Secondly, the critical film thickness of TFL at high speeds is much higher than the typical ones at lower speeds. The thick film under TFL helps to ensure a stable lubrication for quite a long time before the failure.

\subsection{TFL at high applied load}

Lubrication properties and mechanism have been extensively discussed at low and moderate applied loads. In practical applications, high contact pressures of up to $3 \mathrm{GPa}$ or higher always lead to the failure of whole tribo-system. Although this phenomenon has attracted interest, its study has been limited by technology and instrumentation.

Zhu $[84,85]$ presented a big deviation of the film formation from the classic Hamrock-Dowson theory by conducting numerical studies. Krupka et al. [86] demonstrated the thin film lubrication properties of hexadecane trapped between a tungsten carbide ball and a sapphire disk at a high pressure up to $3 \mathrm{GPa}$. Similar deviation from Hamrock-Dowson prediction was also observed, as shown in Fig. 11. Xiao et al. $[87,88]$ successfully conducted experiments on the thin film lubrication properties of oils by pressing a steel ball against a sapphire disc. It was found that oils (silicone oil and poly alpha olefins) with different viscosities exhibit different performances on film formation at high pressures. In terms of poly alpha olefins (PAO), the speed index is reduced gradually with increasing viscosity at both high and low speeds [88] as shown in Fig. 12(a). For silicone oils, the speed index is found not to be sensitive to the viscosity, as there is only slight reduction at low speed [87, 88], as shown in Fig. 12(b). Xiao et al. attributed such phenomenon to the fluidities and the molecular structures of the lubricants [87]. The compressibility of the lubricants has been indicated to be responsible for the film formation performance at high pressure.

Ionic liquids in high confinement were also investigated by Xiao et al. [89], because of their unique properties. The longer length of the alkyl side chain

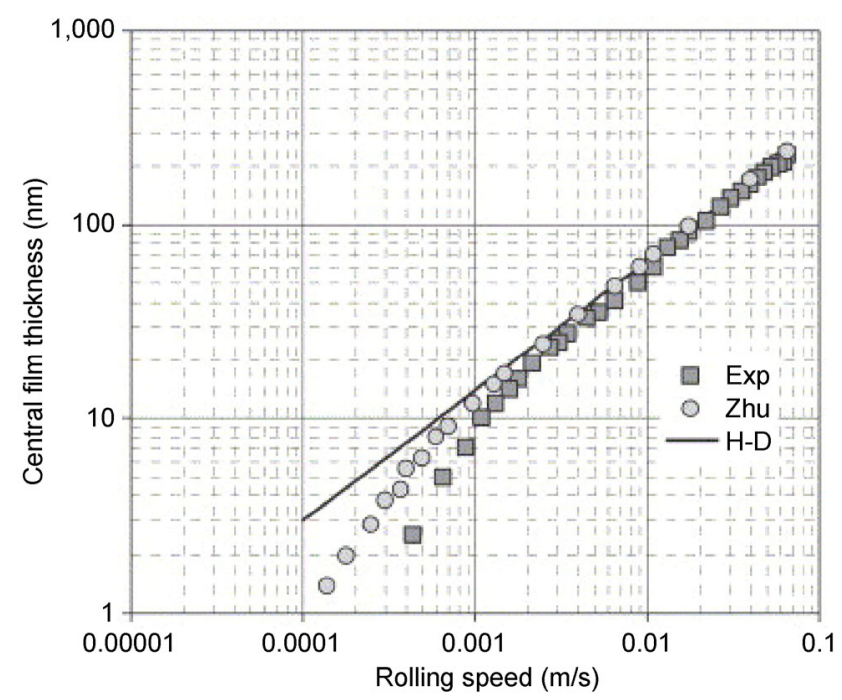

Fig. 11 Film thickness values of hexadecane obtained at maximum Hertz pressure of $2.942 \mathrm{GPa}$ reported by Krupka et al. [86]. Copyright 2006, Elsevier Ltd. 
of the ionic liquid results in lubrication films that are thicker than those of silicone oils with similar viscosity, as shown in Fig. 13. It suggests that ionic liquids could be excellent lubricants at high pressure, due to the effective aggregation of molecules in the contact area.

\subsection{Effect of molecular polarity on TFL}

The central idea of TFL theory is the surface-and friction- induced molecular ordering and packing. Zhang et al. [74, 90] found that the degree of order of molecules in nano lubricating film is significantly affected by the polarity of the lubricant molecules. To measure both the film thickness and the molecular structures simultaneously, an in-situ system was developed by combing the interferometer and Raman spectra technique. Liquid crystal 5CB was used as the lubricant with polar molecules, while hexadecane was used as the nonpolar lubricant. The 5CB molecules are found to be isotropic and vertical to the solid surface in the static film in the contact region, while n-hexadecane molecules are found to exhibit a more extended chain structure between static contacted surfaces compared to molecules in bulk. It should be noted that the results obtained during the lubricating process will be of great significance. The orientation of $5 \mathrm{CB}$ molecules varies with the speed and film thickness [74,90]. When the lubrication regime is transferred from TFL to EHL, the detected $5 \mathrm{CB}$ molecules change orientation, from perpendicular
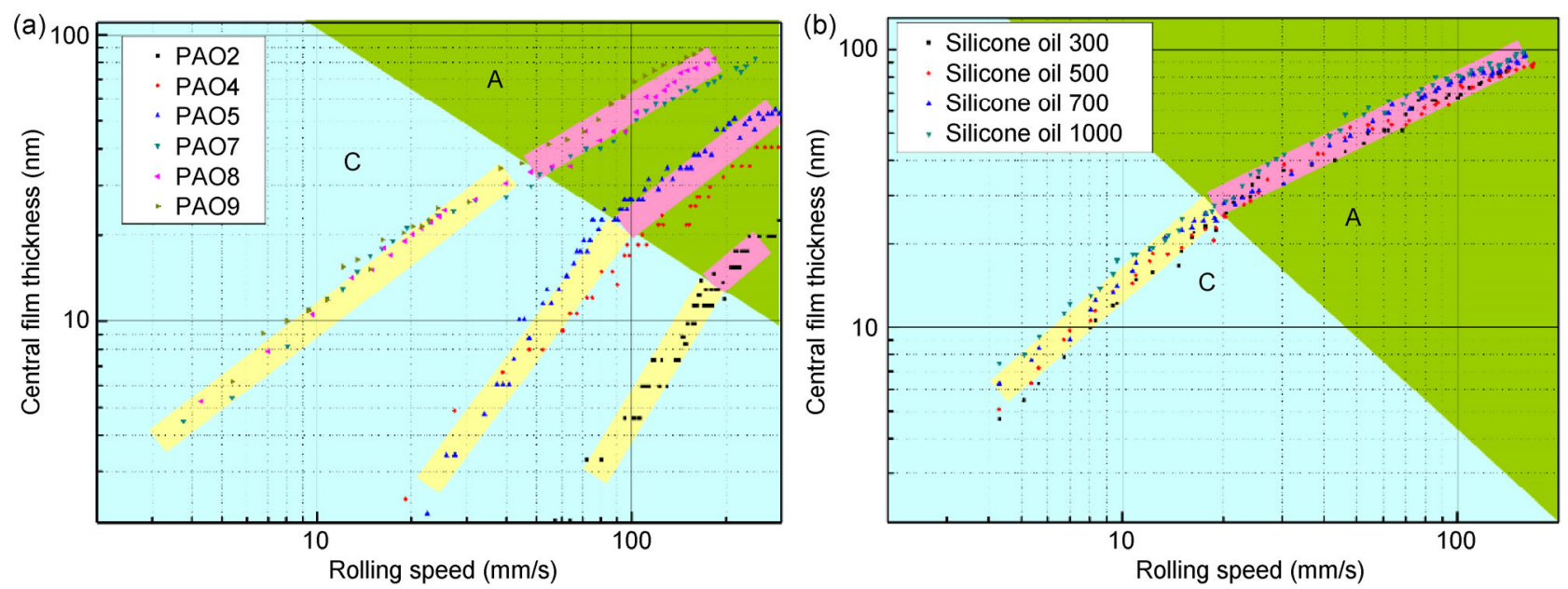

Fig. 12 Film formation of (a) PAO oil and (b) silicone oil obtained at high pressure of 3GPa by Xiao et al. [88].
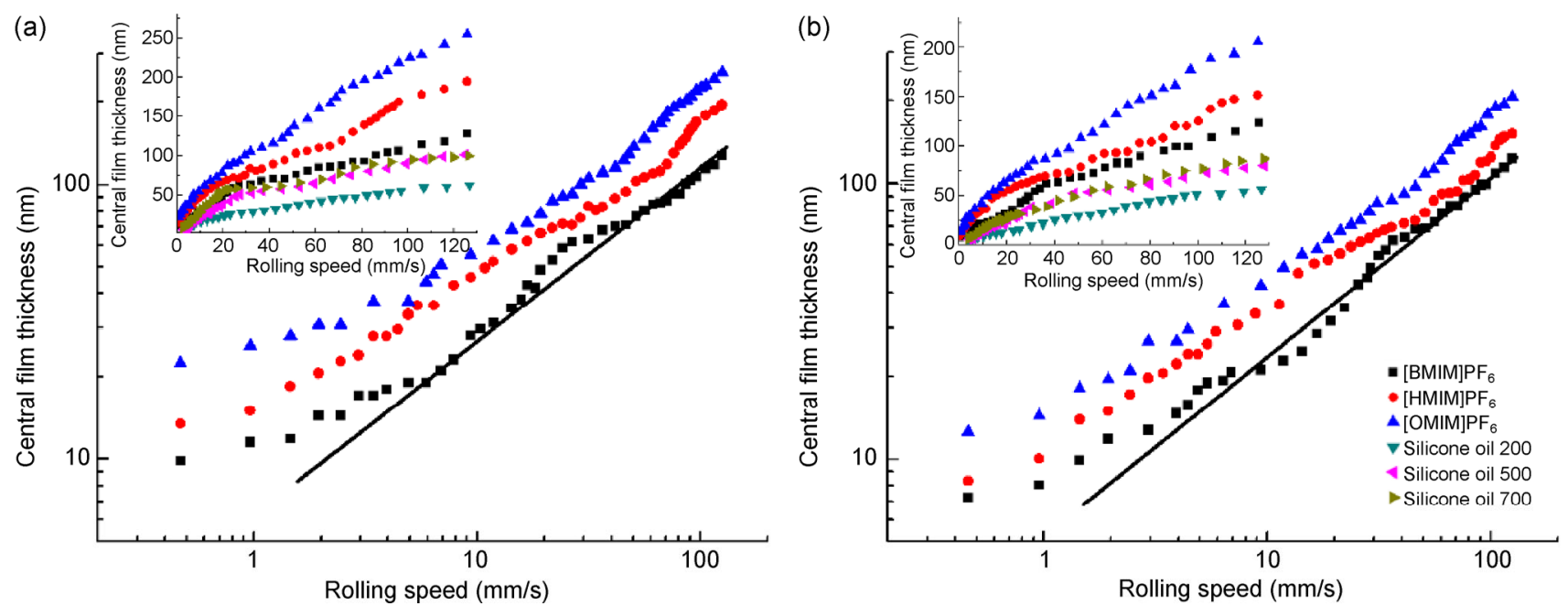

Fig. 13 Film formations of ionic liquids and silicone oils at (a) pressure of $1 \mathrm{GPa}$, (b) $3 \mathrm{GPa}$ measured by Xiao et al. [89]. Copyright 2010, Springer Science+Business Media, LLC. 
to the surface to parallel to the rolling direction, as a result of the shear effect. Thus, the molecular orientations of 5CB in different layers, i.e., absorbed layer, ordered layer and fluid layer, can be described in graphical models, as shown in Fig. 14 [90], taking advantage of the in-situ polarization Raman spectra.

In contrast to polar molecules, hexadecane molecules in the lubrication gap are more disordered than those in the bulk of the liquids when the rolling speed is high. When the lubrication regime transitions form EHL to TFL regime, a shear-induced anisotropic structure can be finally formed [90] along the rolling direction.
Furthermore, molecules of liquid crystal 5CB have also been investigated as additives in polar and nonpolar solvents [90]. Zhang and Luo suggested the molecular mode to describe the difference between polar and nonpolar solvents in TFL regime, as shown in Fig. 15 [90], based on the in-situ experimental results. As a result of the surface effect and the absorption process, nonpolar solvent molecules (hexadecane) are less distributed in the contact region compared to the polar solvent molecules (decanol). There is intensified competition between 5CB molecules and the solvent molecules, especially on the solid surfaces. The orientation along the rolling direction is found to still (a)

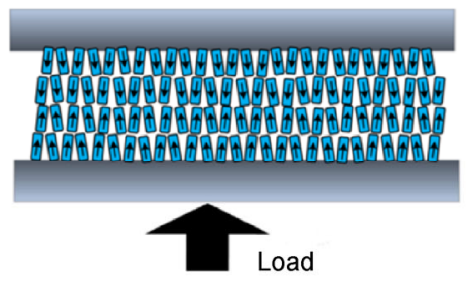

(b)

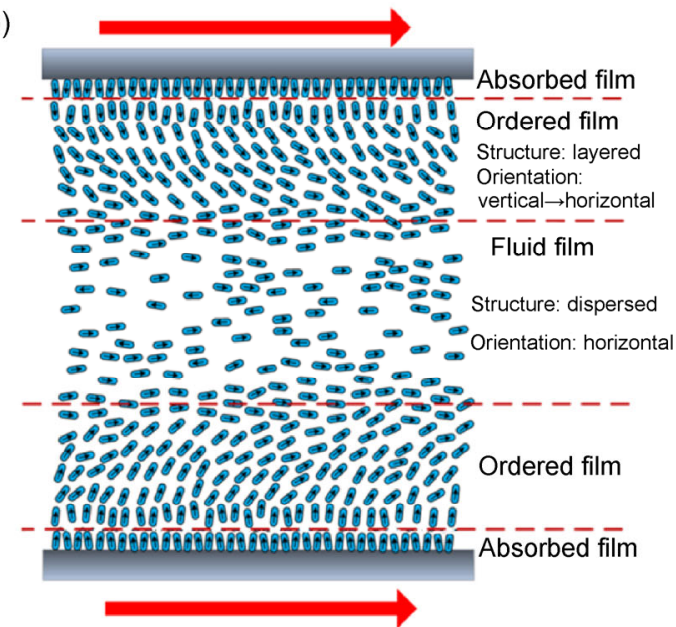

Fig. 14 Molecular models of liquid crystal 5CB (a) in static contact and (b) in TFL, proposed by Zhang et al. [90].
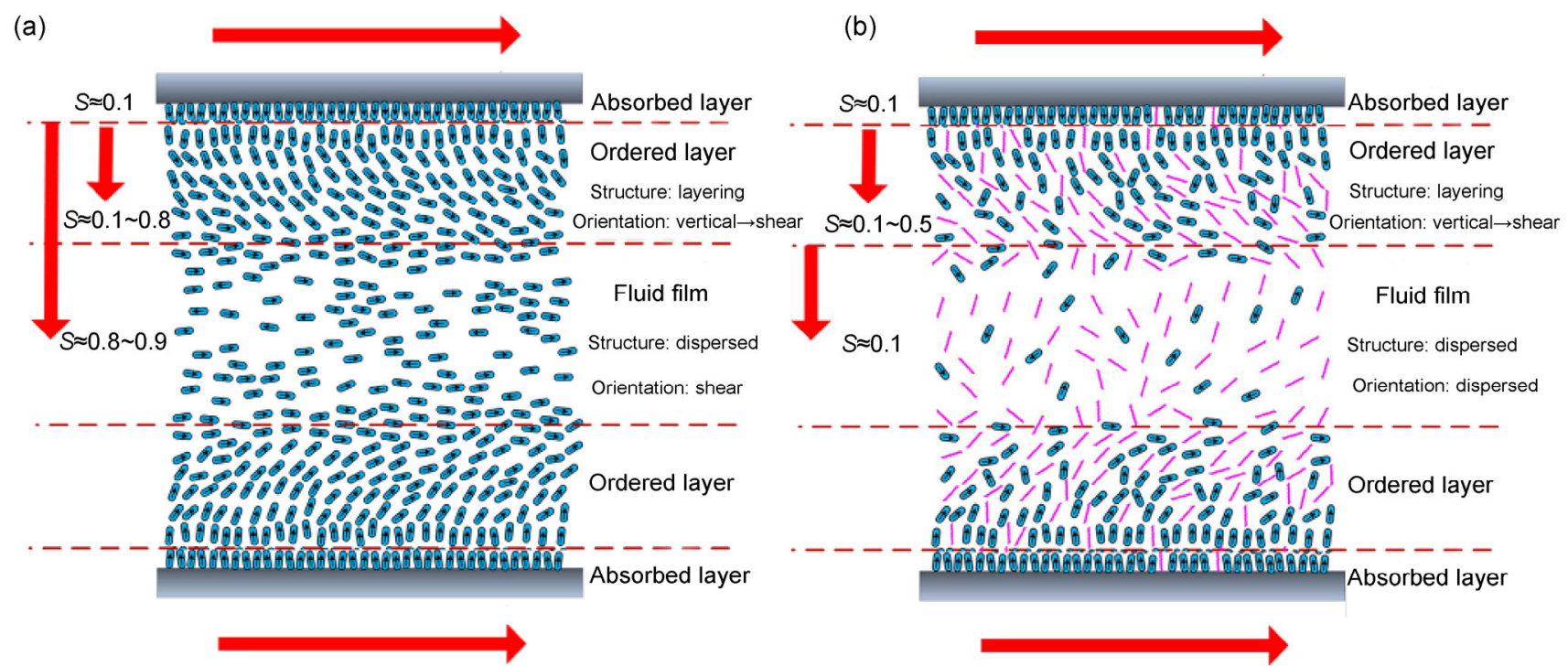

Fig. 15 Molecular structures of 5CB in (a) nonpolar solvent (hexadecane) and (b) polar solvent (decanol), proposed by Zhang and Luo [90]. 
exist in the ordered film in nonpolar solvents, but it disappears in polar solvents.

\subsection{Effect of slide ratio on TFL [38]}

The film formation of lubricants (white oil) was demonstrated to be independent of the slid ratio and dependent on the average speed of two surfaces in the TFL regime, as shown in Fig. 16 [4, 38], which is similar to the situation in the EHL regime. Based on experimental results, Luo et al. $[4,38]$ concluded that when the film thickness is higher than around $30 \mathrm{~nm}$, the film thickness will be independent of the slide ratio, but dependent on the average speed of the two solid surfaces in relative motion, except for in a pure sliding condition, in which the film will collapse.

\subsection{Effect of solid surface energy on TFL [20]}

It is established that the surface tension and surface energy play important roles in wetting and absorption processes. Without a doubt, the molecules on surfaces will also be affected by the surface energy. This ubiquitous physical basis can contribute to the occurrence of interesting phenomena in tribology applications, especially with regard to thin film lubrication. As shown in Fig. 17, the effect of surface energy on film formation was investigated by Luo and Wen $[4,19,20]$ by conducting experiments on different solid surfaces with different surface energies. Furthermore, the deposition approach (ion beam assisted deposition) was used to access different coatings on steel balls. In Fig. 17 [4, 20], the film thickness of mineral oil on different kinds of coatings is measured. Please check The surface energy values of the Fe coating and $\mathrm{Cr}$ coating are similar to each other, resulting in a similar film thickness for mineral oil in the TFL regime. The surface energy of the Al coating is the lowest among the four kinds of materials, resulting in the lowest film thickness for mineral oil.

While looking at the film thickness-duration curve, as shown in Fig. $18[4,20]$, the increment of film thickness of mineral oil on the Fe coating was found to be about $15 \mathrm{~nm}$, i.e., from $15 \mathrm{~nm}$ to about $30 \mathrm{~nm}$, in 60 min duration, which is obviously larger than that of $10 \mathrm{~nm}$, i.e., from $5 \mathrm{~nm}$ to about $15 \mathrm{~nm}$, on the $\mathrm{Al}$ coating. Furthermore, the static films after rolling for $60 \mathrm{~min}$ also exhibited an increased thickness on

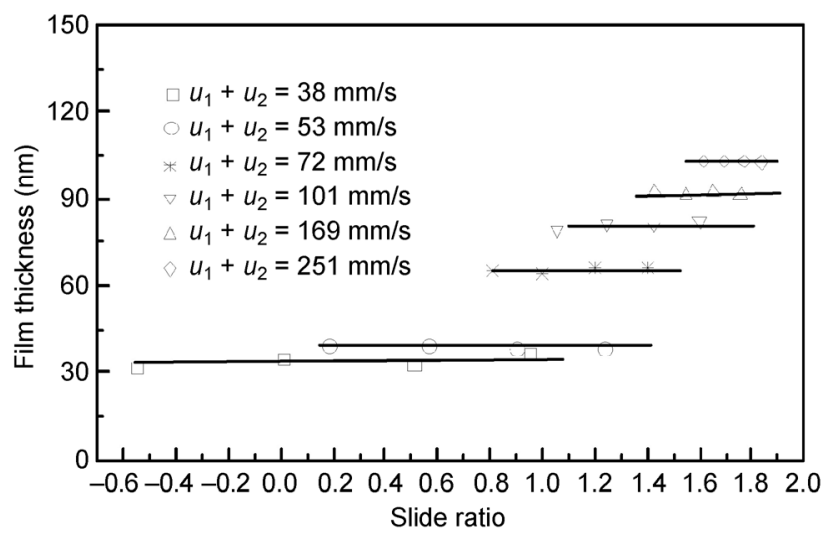

Fig. 16 Effect of slide ratio on the film thickness of white oil $+5 \%$ nonionic acid, at a temperature of $20{ }^{\circ} \mathrm{C}$ and load of $2 \mathrm{~N}$, reported by Luo et al. [4, 38].

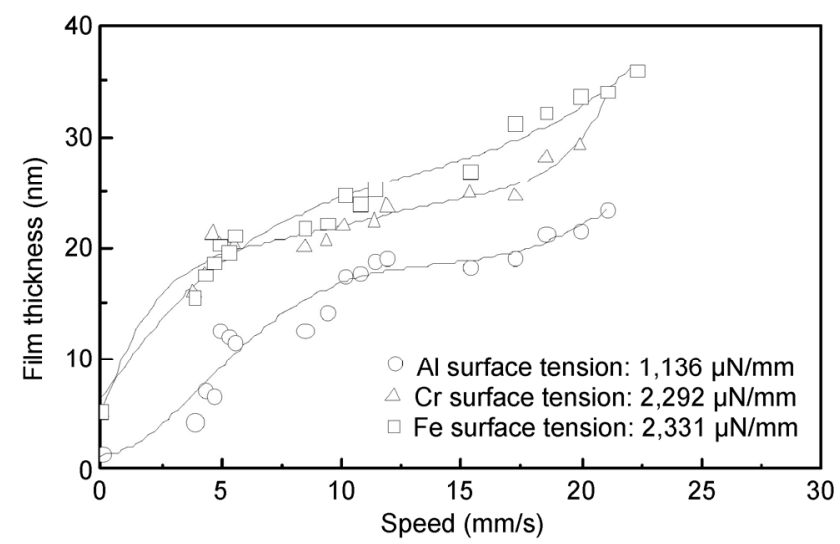

Fig. 17 Film formation of mineral oil on different substrate under a load of $4 \mathrm{~N}$, measured by Luo et al. [4, 20].

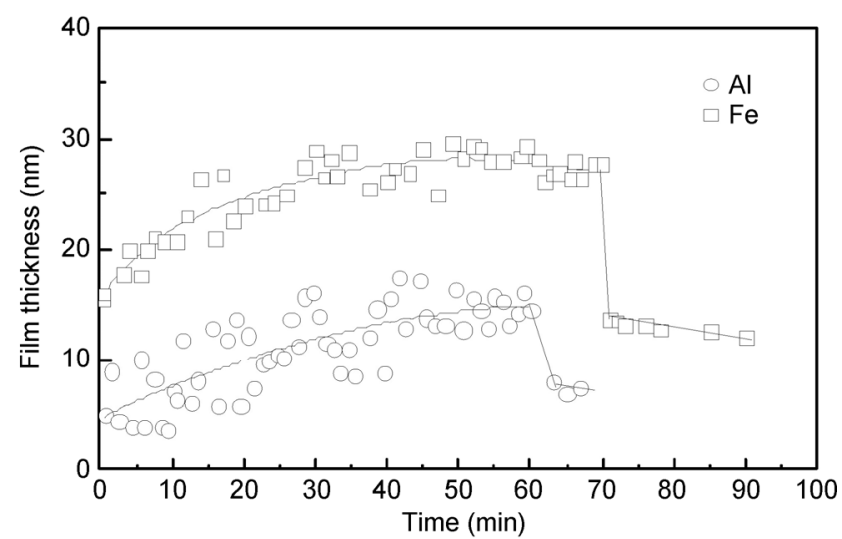

Fig. 18 Film thickness versus time of mineral oil on different substrates under a speed of $4.49 \mathrm{~mm} / \mathrm{s}$, a load of $7 \mathrm{~N}$, measured by Luo et al. $[4,20]$.

the Fe coating, which was around $13 \mathrm{~nm}$, and were thinner on the $\mathrm{Al}$ coating, with a thickness of $7 \mathrm{~nm}$. Thus, it was concluded that, for mineral oil, higher 
energy surfaces will result in thicker lubricating films in the TFL.

\section{Aroused studies and advances}

\subsection{Advances of TFL studies under external electrical fields [52, 91-95]}

Due to the potential applications of confined films in both industrial and scientific fields, their properties and mechanisms external electric fields have caused extensive and great concern in the past few of decades. The behaviors of liquid trapped between solid surfaces in contact have also been investigated [96-99]. It has been reported that phase transitions, molecular structures and flow properties of liquids, such as water $[96,97]$ and ionic liquids $[98,99]$, in confinement can be easily observed under external electric fields.

In the field of tribology, the failure of machinery and elements operating in electric fields is mostly due to electrical damage, which has called for a deep exploration of the underlying mechanisms, especially when the rubbing surfaces are in the TFL regime, as the film thickness is much lower than that in the EH regime. Since the TFL theory was proposed, many studies on the TFL regime under external electric field have been conducted. Their findings support the hypothesis that enhancement of the degree of molecular order will happen more easily in polar liquids [100-105].

Liquid crystals are known as good lubricants with polar molecules. Luo et al. [91] studied the film formation performances of liquid crystals mixed with hexadecane in an external electric filed, on the set-up shown in Fig. 19 [91]. A thickened film with increasing applied voltage has been observed, as shown in Fig. 20(a) [91], which is much thicker than that predicted by the Hamrock-Dowson equation. A similar thickening process can be also be observed in polar hexadecanol, as shown in Fig. 20(b) [91], which can be attributed to the increased effective viscosity of liquid in the contact area near the solid surfaces. Such increases of the effective viscosity has been well explained by Luo et al. [91], who conclude that the electric field induces rearrangement of polar molecules. Thus, it can be indicated that there is a maximum applied voltage that enables the arrangement of molecules. Even if the applied voltage goes beyond this value, the film

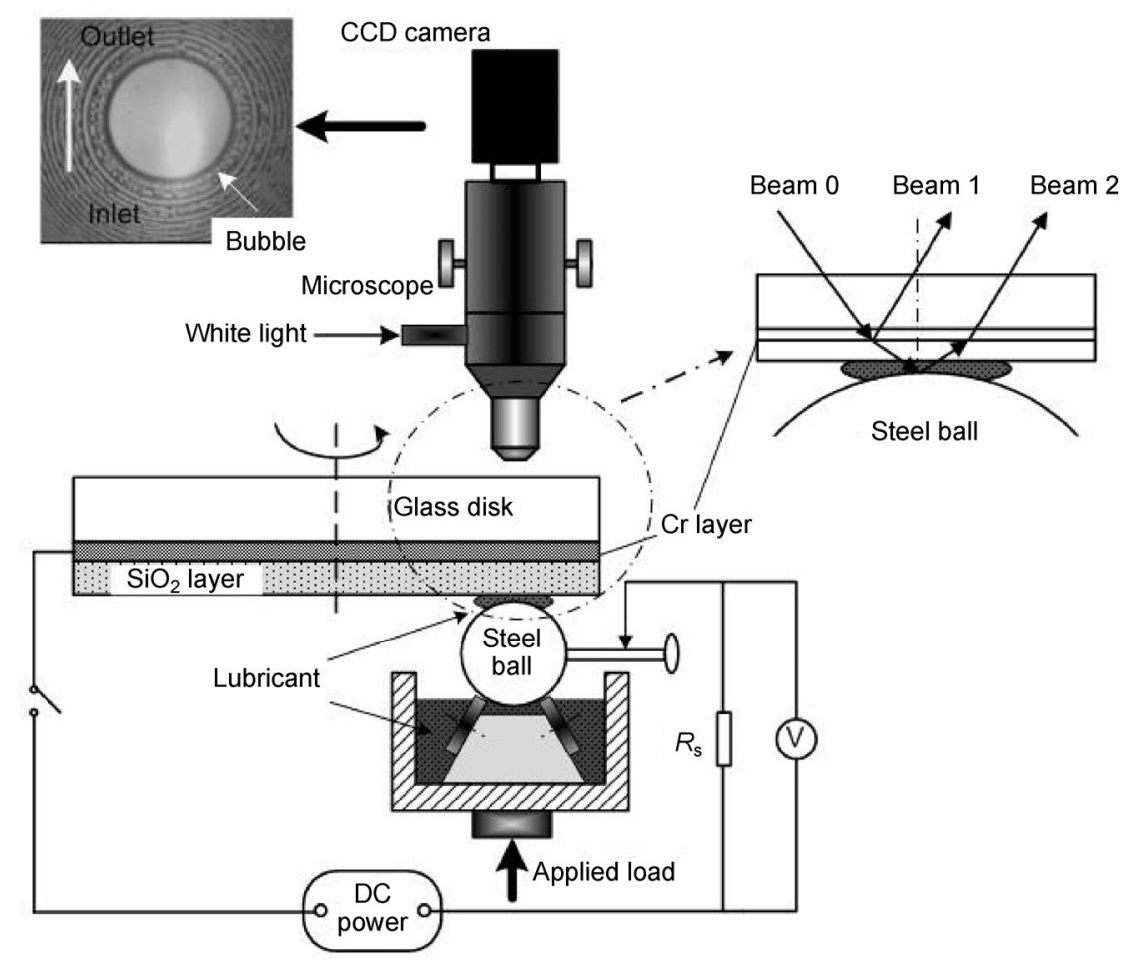

Fig. 19 The sketch of the experimental setup for TFL under external electrical field, developed by Xie et al. [91, 92]. Copyright 2004, AIP Publishing LLC. 
thickness will no longer increase, because the molecules would have reached their maximum degree of re-arrangement [91]. Similar enhancement of film thickness, which suggests the formation of a strongly regular structure, has also been demonstrated by Xie et al. [92], who used another kind of polar liquidionic liquid.

The film formation characteristics of straight-chain aliphatic liquids under external electric fields in TFL were also investigated by Xie et al. [93]. Based on their experimental results, the head group of molecules and the alkyl chain length have been found to be able to significantly affect the formation of interfacial ordered structures in external electric fields due to the dipole orientation. Further studies conducted by Xie et al. [94] demonstrated a "freezing" of lubricant in a nano gap in TFL regime [94], which can be observed for both polar liquids and nonpolar ones. The freezing process of $n$-hexadecane with a thickness of around $12 \mathrm{~nm}$, as demonstrated in Fig. 21 [94], can be explained by the ordering alignment in the central contact region under the external electric field.

Another new phenomenon, emergence of gas microbubbles, was found surrounding the contact area under the external electric field by Luo et al. [95, 106-108]. Luo and $\mathrm{He}$ [95] demonstrated the emerged micro-bubbles under an electric field by trapping glycerin, glycol, hexadecane and liquid paraffin in nano gaps that ranged from $4 \mathrm{~nm}$ to $10 \mathrm{~nm}$ under an electric voltage larger than 5 V. Gas micro-bubbles can be observed to first emerge at the edge of the central contact region and then escape from the contact rapidly, as shown
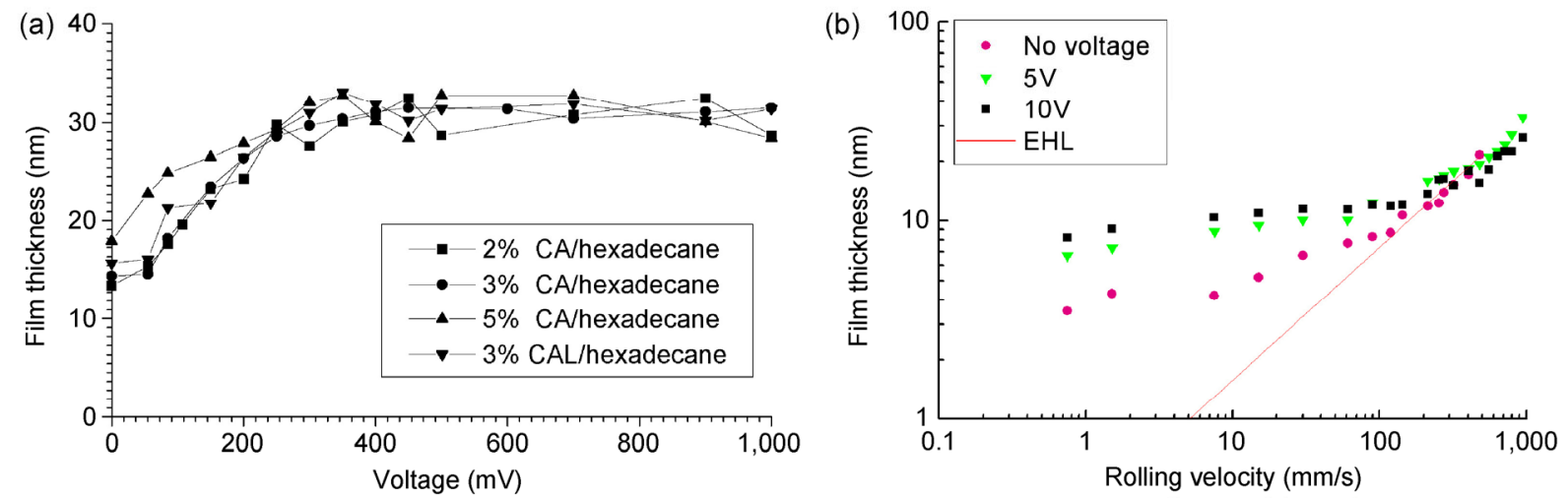

Fig. 20 Effect of DC voltage on film thickness of (a) mixtures of LCs and hexadecane, load: $0.174 \mathrm{GPa}$, rolling speed: $68 \mathrm{~mm} / \mathrm{s}$; (b) hexadecanol, load 4 N, which was reported by Xie et al. [91]. Copyright 2004, AIP Publishing LLC.

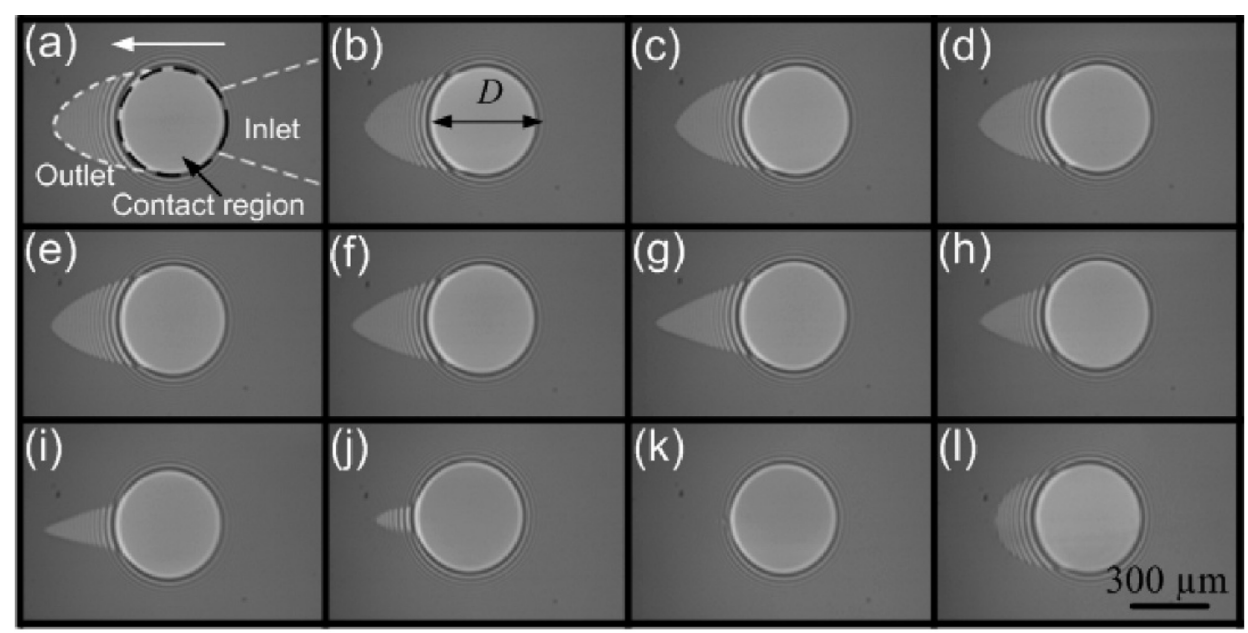

Fig. 21 "Freezing" of liquid in a nano gap by using n-hexadecane under different dc voltages, observed by Xie et al. (a) 0 V, (b) 10 V, (c) $20 \mathrm{~V}$, (d) $30 \mathrm{~V}$, (e) $40 \mathrm{~V}$, (f) $50 \mathrm{~V}$, (g) $60 \mathrm{~V}$, (h) $70 \mathrm{~V}$, (i) $80 \mathrm{~V}$, (j) $90 \mathrm{~V}$, (k) $98 \mathrm{~V}$, and (l) $10 \mathrm{~s}$ after the removal of the EF [94]. Copyright 2010, American Chemical Society. 
in Fig. 22 [95]. Based on their experimental results, a critical voltage has been defined, above which bubbles will emerge in an external electric field. With regard to different lubricants trapped between two surfaces (steel ball and silica-on-chromium coated glass disc), different critical voltages are obtained. Polar liquids (glycerin and glycol) produce many bubbles that are larger in size and which have a longer survival life, compared to nonpolar liquids (hexadecane and liquid paraffin). They attributed the formation of such bubbles to the liquid surface vibration.

Subsequently, more experiments were conducted by Xie et al. [106-108] on the nano confined film in an external electric field to better understand the basic of the electric-filed-induced bubbles. By using polyethylene glycols (PEG) aqueous solutions and glycerin solutions as confined liquids, they were able to conclude that the critical voltage for the appearance of micro gas bubbles is strongly dependent on the viscosity of liquid and the surface tension [107].

\subsection{Advances of TFL studies in aqueous lubrication} [52]

Nowadays, one of research hotspots in the tribology field is aqueous lubrication, due to the growing energy crisis and environmental pollution. Great efforts have

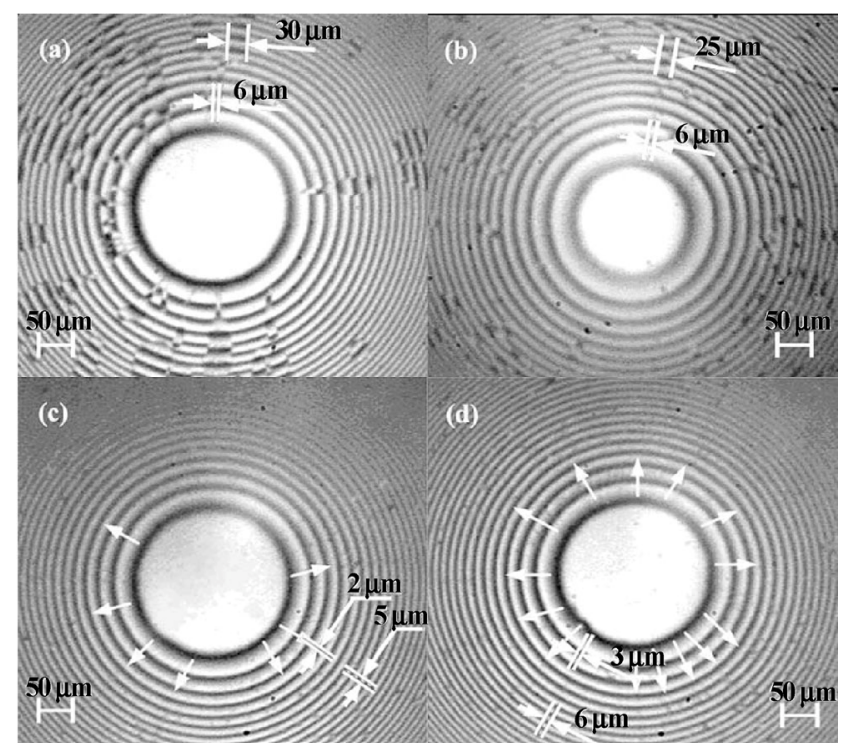

Fig. 22 Microbubbles in electrical field observed by Luo et al. by using different lubricants, (a) glycerin, $6 \mathrm{~V}$; (b) glycol, $5 \mathrm{~V}$; (c) hexadecane, $9 \mathrm{~V}$; and (d) liquid paraffin, $7 \mathrm{~V}$ [95]. Copyright 2008, Springer Science+Business Media, LLC. been made by tribologists from both industry and academia to reveal the mystery of aqueous lubrication. It has been recognized that water will exhibit totally different with common oil while acting as a lubricant, especially when trapped in a nano-gap, due to the polarity of the water molecules. In the past two decades, the presentation and development of TFL has strongly encouraged new techniques and scientific studies, as well as provided new perspectives to explore the properties and mechanism of aqueous lubrication. Thanks to these studies, better applications of aqueous lubrication can be expected.

The film formation performances of surfactant solutions have been investigated by Ratoi and Spikes [109]. The amphiphilic molecular structure with hydrophilic heads and hydrophobic tails induces the alignment and aggregation of surfactant molecules on the solid surface. Thus, although the film forming characteristics of surfactant solutions were found to be related to the concentration, type and $\mathrm{PH}$ value of the surfactant solutions, thickened films deviating from the Hamrock-Dowson prediction can be always observed, as shown in Fig. 23 [109], which are confirmed to be located in the TFL regime and are caused by the adsorption and packing of mono- or bi-layers on the surfaces. The evidence of the adsorption and packing of surfactant molecules on surfaces has also been provided by Boschkova et al. [110-112], who used cation, amphiphile and gemini surfactants solutions as lubricants. By employing various approaches involving QCM (quartz crystal microbalance), SFA and AFM (atomic force microscope), Boschkova et al. were able to present the model of structured surfactant molecules in the nano-confined gap. They

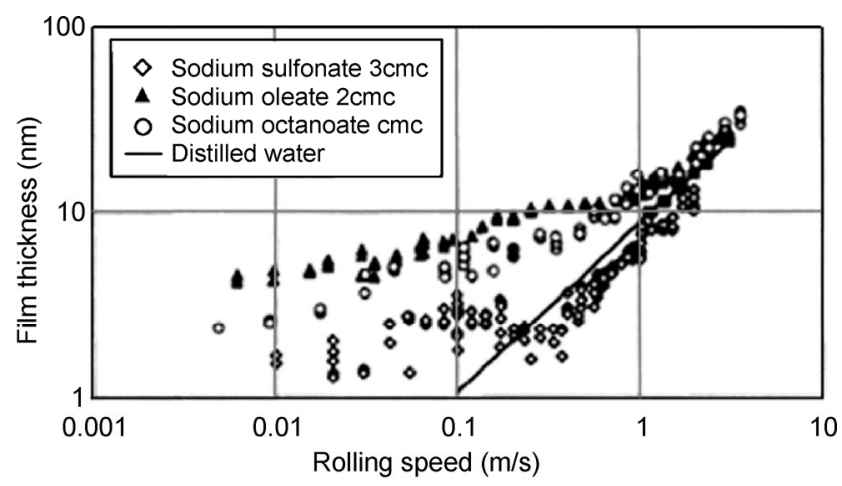

Fig. 23 Film formations of aqueous surfactant solutions presented by Ratoi and Spikes [109]. Copyright 1999, Taylor \& Francis. 
attributed the favorable film formation performance and pressure resistance capability to the formation of the neatly arranged mono- or multi- layers on solid surfaces. Liu [113] also reported that, due to the adsorption and molecular ordered structures on solid surfaces, the film formation of ionic surfactants solutions can be significantly increased beyond the prediction offered by the Hamrock-Dowson equation.

Similar phenomena in the TFL regime have been found by using polymer aqueous solutions. Lee et al. demonstrated a good film formation ability of poly(L-lysine)-gpoly (ethylene glycol) solutions [114] in metal-oxide-based tribo-systems, with an enhanced film thickness in TFL regime. Plaza et al. [115] demonstrated excellent tribological performance by using polyethoxyglycol esters of dithiphosphate acid derivatives aqueous solutions.

Aqueous emulsions have been widely used as lubricants in manufacturing applications. Inspired by the TFL theory, Ma et al. [116-122] attempted to investigate the film formation capabilities of aqueous emulsions with extremely low oil concentrations. They succeeded in getting notably thick lubricating films even when using ultra-low oil concentrations down to $0.005 \mathrm{vol} \%$ [119] between the steel ball and the coated glass disc, which is dramatically comparable to the film thickness of $100 \%$ pure oil at low speeds, as shown in Fig. 24 [119]. Even more noteworthy is that at higher speed (above around $0.2 \mathrm{~m} / \mathrm{s}$ ), where emulsions with normal concentration will always encounter film thickness collapse, the emulsions with

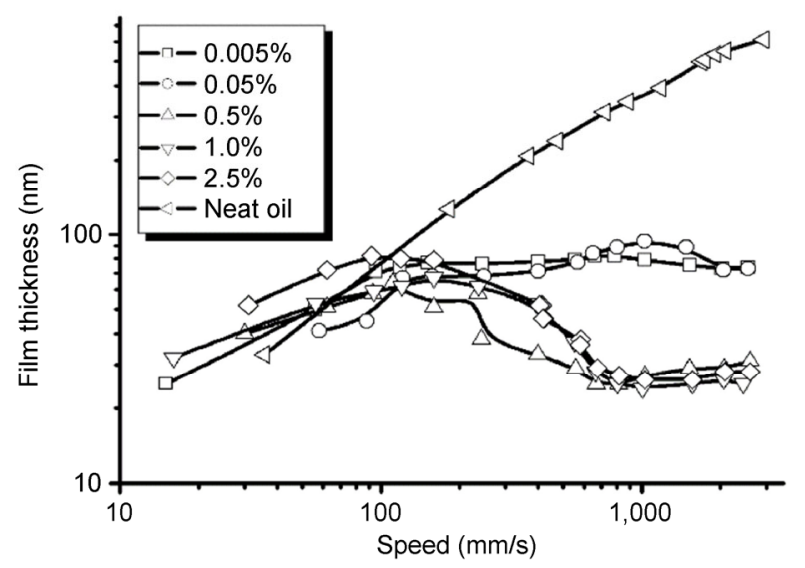

Fig. 24 Film formation of aqueous emulsions with oil concentrations measured by Ma et al. [119]. Copyright 2009, Elsevier B.V. ultra-low oil concentrations exhibit tenacious thick lubricating films of around $100 \mathrm{~nm}$. To explain this favorable phenomenon, Ma et al. [120] proposed the re-emulsification and oil pool theories based on both experimental and theoretical studies. They conducted experiments to directly observe the micro contact area [122], and found that an oily pool will be formed around the contact region, as demonstrated in Fig. 25 [122], and thin oil film wetting will be observed on the surfaces of the contact region. They suggested that such excellent film formation abilities of emulsions with ultra-low oil concentrations can be attributed to the tenacious wetting oil nanolayer on the solid surfaces.

\subsection{Advances of TFL studies in liquid superlubricity $[52,125]$}

Attempts to effectively reduce friction can be retrospect to antiquity. Superlubricity has been always a great concern, since it was proposed by Hirano and Shinjo
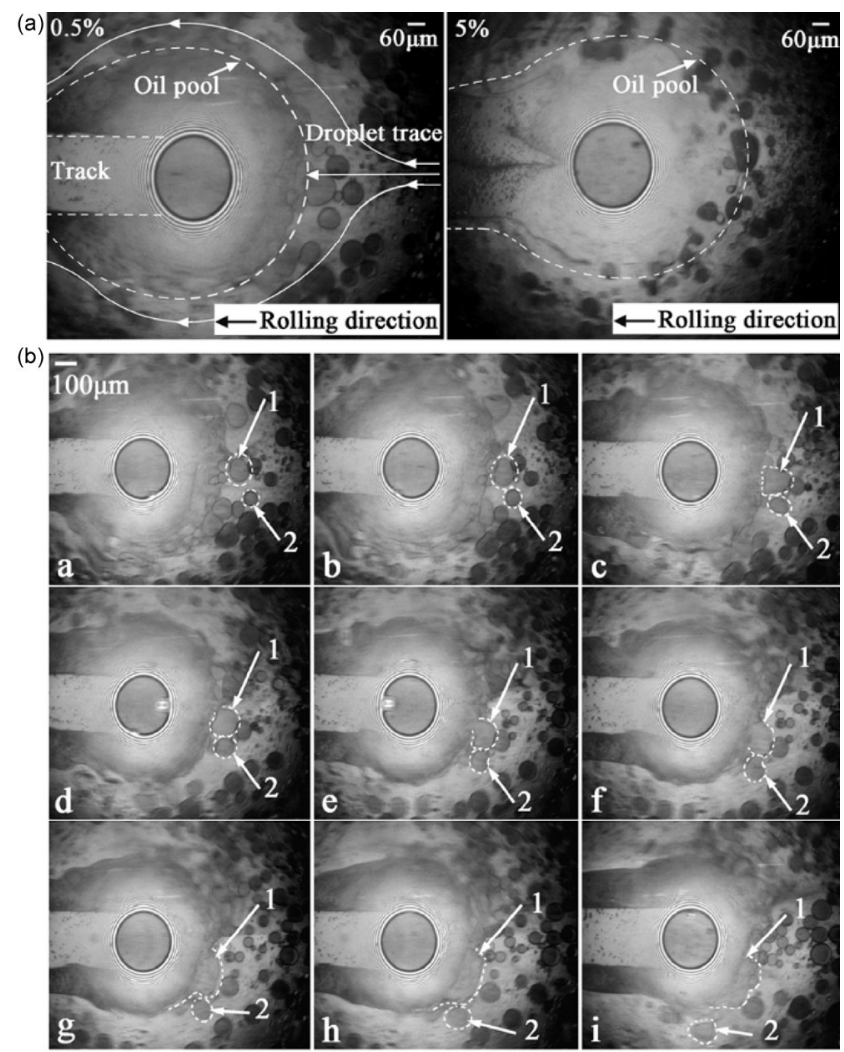

Fig. 25 Observation on the aqueous emulsion under a rolling speed of $0.005 \mathrm{~m} / \mathrm{s}$, achieved by Ma et al. (a) Trajectories of oil droplets; (b) two kind to typical droplets [122]. Copyright 2012, AIP Publishing LLC. 
$[123,124]$ around 26 years ago. People have succeeded in obtaining superlubricity in both solid and liquid tribosystems. In the past two decades, many liquids have been found to have superlubricity abilities; however, the mechanism that achieves superlubricity is still too dubious for industry applications. Studies on revealing the underlying mechanism have attracted more candidates for liquid superlubricity, especially on the lubrication states in both the boundary and TFL regimes.

Superlubricity liquids have been found to mainly focus on three kinds of materials [125]. Water on ceramic materials was often reported to behave as a superlubricity tribosystem [126-130]. Kato and Adachi's group finally owed to the formation of the silica layers induced by the running-in process, as well as the hydrodynamic lubrication induced by the significant pressure decline $[125,130]$.

Polymer solutions have been confirmed to be able to provide excellent lubrication between rubbing surfaces in TFL or boundary regimes. Friction coefficients lower than 0.0006 have been obtained by Klein's group [131-133], using charged polymer solutions trapped between two mica surfaces, in a gap of a few tens of nanometers. It has been indicated that such low friction is caused by the resistance to mutual interpenetration of the attached polymer brushes [131,132]. Kenausis et al. [134] conducted similar experiments to access superlubricity by using poly-lysine (PLL) molecules grafted by polyethylene glycol (PEG) in aqueous solutions, which are firmly attached to the underlying substrates. A friction coefficient less than $10^{-4}$ was successfully obtained.

Other substances with superlubricity characteristics in the TFL regime are small molecular solutions-acid solutions and alcoholic solutions, or their mixtures, for instance, which have been discovered by Luo et al. [135-138]. A solution of phosphoric acid was found to be unique, providing an extremely low friction coefficient that was less than 0.004 by Li et al. [135], Ma et al. [136] and Li et al. [137, 138], who achieved superlubricity with alcohols and acids solutions successively. They suggested that the superlubricity of acid and glycerol solutions resulted from a shear-induced hydrogen network structure in a nano-gap, as shown in Fig. 26 [137], which can sustain a high pressure even up to 1.6 GPa. Based on this concept, they succeeded in getting superlubricity by mixing polyhydroxy alcohols and acid solutions [138]. Superlubricity achieved with such mixtures was found to be dependent on both the concentration of polyhydroxy alcohol and the number of hydroxyl groups, but not the number of carbon atoms and the arrangement of hydroxyl groups. Furthermore, superlubricity was also achieved with polysaccharide mucilage extracted from brasenia schreberi by Li et al. [139]. It has been indicated that the ultra-low friction resulted from the formation of hydration layers between the polymer nano-sheets in the polysaccharide gel, as shown in Fig. 27 [139]. They attribute the mechanism of liquid superlubricity to mechanical effects and chemical effects.
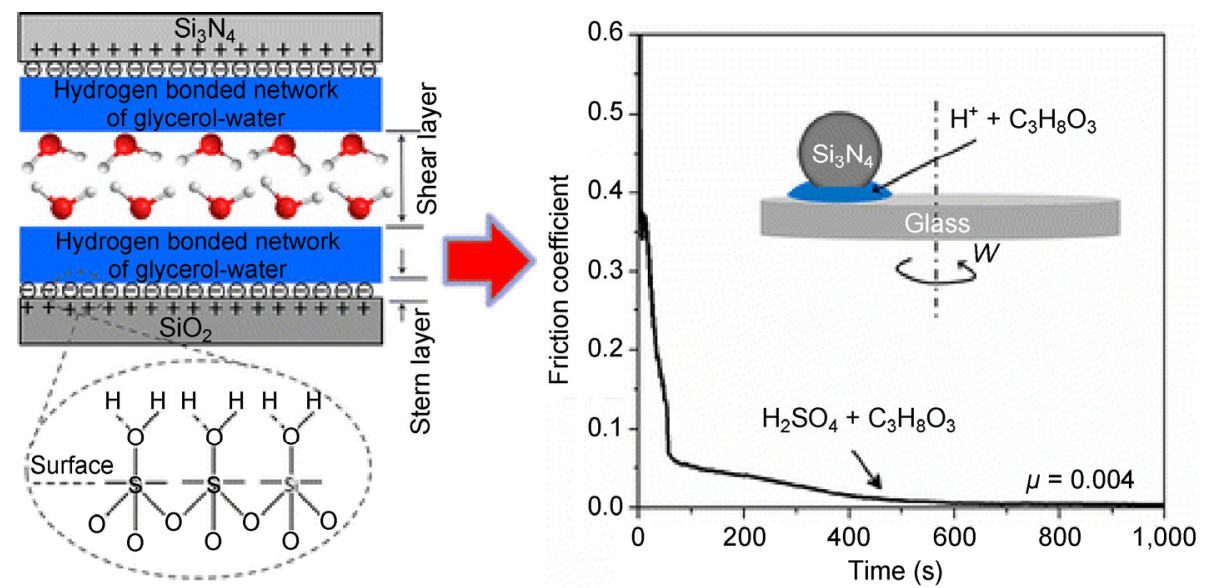

Fig. 26 Superlubricity achieved with mixtures of acids and glycerol reported by Li et al. [135]. Copyright 2013, American Chemical Society. 


\subsection{Advances of TFL studies at molecular level}

One of the main ideas of the TFL theory is surface and friction-induced molecular ordering and packing, which has been calling for direct experimental evidence in the past two decades since TFL was proposed. Techniques facilitating the direct measurement of molecular orientation and arrangement of molecules in the nano-lubrication film will shed new light on revealing the underlying mechanism of TFL.

During the TFL lubrication process, lubricant molecules in each layer align in various patterns. This result revealed a new approach for investigating lubricants at the molecular level. Gao et al. [140, 141] used in-situ Raman spectra to explore the molecular structure and orientation of lubricant molecules in TFL regime by trapping different liquid crystals between two solid surfaces. Nematic liquid crystals $(5 \mathrm{CB}, 6 \mathrm{CB}$,

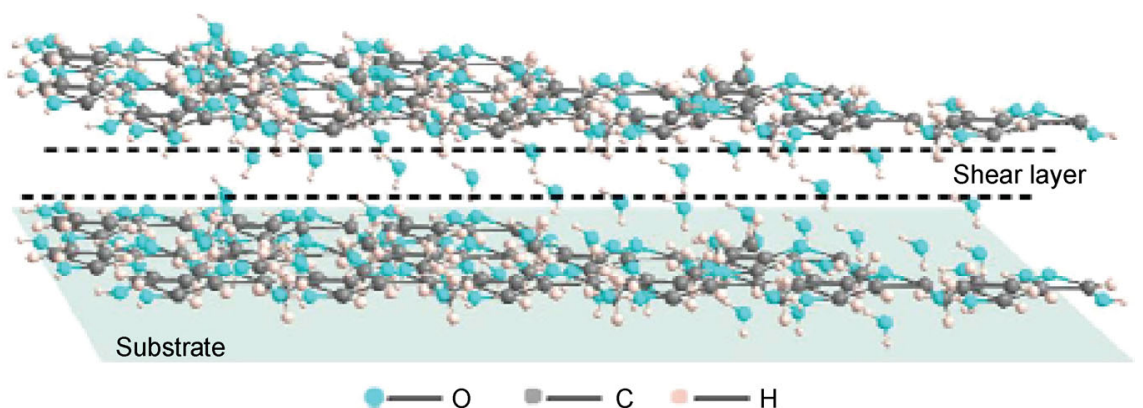

Fig. 27 Molecular structure of polysaccharide extracted from the B.S sample reported by Li et al. [137]. Copyright 2012, American Chemical Society.
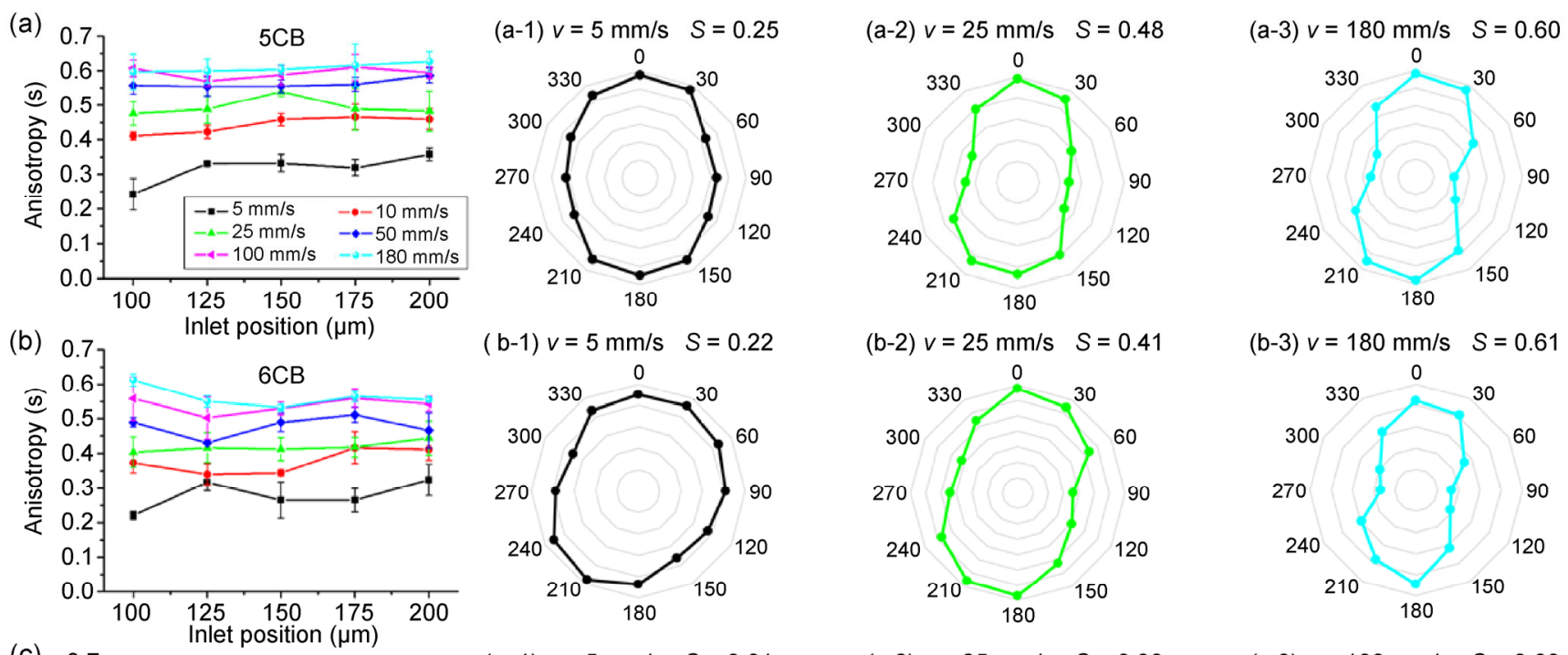

$(b-1) v=5 \mathrm{~mm} / \mathrm{s} \quad S=0.22$

(b-2) $v=25 \mathrm{~mm} / \mathrm{s} \quad S=0.41$
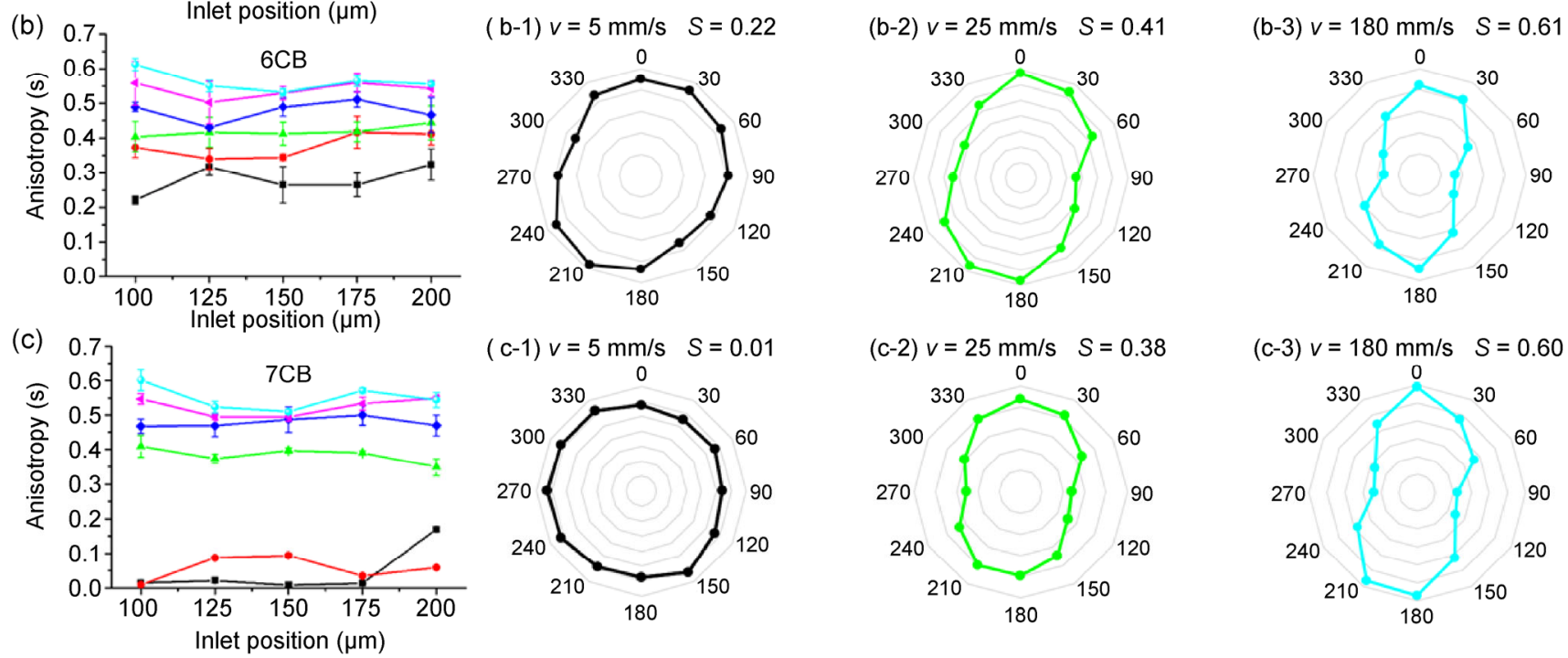

Fig. 28 Molecular orientation in a nano gap measured by Gao and Ma et al.[140]. (a) Anisotropy for 5CB molecules in the inlet region, (a-1) to (a-3) represent the relative value of Raman intensity at different $\theta$ recorder at position $(0,100)$ under speed of $5 \mathrm{~mm} / \mathrm{s}, 25 \mathrm{~m} / \mathrm{s}$ and $180 \mathrm{~mm} / \mathrm{s}$. (b) and (c) for 6CB and 7CB, respectively [140]. Copyright 2016, Springer Science+Business Media. 
and 7CB) from the CB family with different lengths of molecular side chains were utilized. As demonstrated in Fig. 28 [140], the liquid crystal molecules are aligned along the rolling direction in the inlet region. The radar curve represents the alignment anisotropy. It can be noticed that the alignment anisotropy obviously increases with speed, while the radar curve changes from a fat ellipse to a rod-like one. One can also observe that the anisotropy decreases with increasing carbon numbers in the flexible alkyl chain region. It has been indicated that both shearing velocity and the alkyl chain length will affect the orientation of liquid crystal molecules confined in a nanoscale gap.

\section{Summary and conclusions}

A remarkable mode of lubrication was revealed two decades ago, termed thin film lubrication (TFL), in which the lubricant film consists of an absorbed film, an ordered film, and a fluid film. TFL has become a great concern in the past twenty years, and attracted the interest of not only tribologists, but also physicists and chemists. In this paper, after a brief review of the history of TFL, as well as a presentation of pertinent theories and models, we have summarized facilities and approaches allowing the study of TFL, and on which TFL has been able to rapidly develop. All the potential techniques have the capability to detect tiny changes at nanometer or sub nanometer scale. With the advanced technologies and instruments, the location of lubrication films in TFL has been shown to be dependent on surface speed, but the dependence deviates from the predictions of the classical theory of EHL. In this lubrication regime, hydrodynamic flow still exists, but the physical and chemical effect of lubricant molecules comes into play. In this paper, we have reviewed studies about the basic properties of TFL, as well as the main factors that influence it. The extensive and comprehensive studies reviewed in this paper have been demonstrated to complete the theory of TFL. Furthermore, to meet the requirement of deeply investigating the lubrication mechanism of TFL, innovative explorations and studies on the TFL have been discussed, providing new perspectives for the development and applications of TFL.

\section{Acknowledgements}

The work was financially supported by the National Natural Science Foundation of China (Nos. 51527901, 51321092, and 51335005).

Open Access: The articles published in this journal are distributed under the terms of the Creative Commons Attribution 4.0 International License (http:// creativecommons.org/licenses/by/4.0/), which permits unrestricted use, distribution, and reproduction in any medium, provided you give appropriate credit to the original author(s) and the source, provide a link to the Creative Commons license, and indicate if changes were made.

\section{References}

[1] Petrusevich A I. Fundamental Conclusions from the Contact-Hydrodynamic Theory of Lubrication. Izv Akad Nauk SSR Otd Tekh Nauk 2: 209-233 (1951)

[2] Dowson D, Higginson G R. A Numerical Solution to the elastohydrodynamic Problem. J Eng Sci 1: 6-15 (1959)

[3] Hardy W B. Collected Works. Cambridge (UK): Cambridge University Press, 1936.

[4] Luo J B. Study on the measurement and experiments of thin film lubrication. Ph.D Thesis. Beijing (China): Tsinghua University, 1994

[5] Luo J B, Wen S Z, Huang P. Thin film lubrication, Part I: The transition between EHL and thin film lubrication. Wear 194: 107-115 (1996)

[6] Reynolds O. On the theory of lubrication and its application to Mr. Beauchamp Tower's experiments, including an experimental determination of the viscosity of olive oil. Philos Trans R Soc London 177: 157-234 (1886)

[7] Dowson D. Elasto-hydrodynamic Lubrication theory for anti-friction bearings. Erdol Und Kohle Erdgas Petrochemie 20(12): 880-\& (1967)

[8] Cheng H S. A numerical solution of the elastohydrodynamic film thickness in an elliptical contact. J Lubr Technol Trans ASME 92: 155-161 (1970)

[9] Hamrock B J, Dowson D. Isothermal elastohydrodynamic lubrication of point contact: Part I-Theoretical formulation. ASME J Lubr Technol 98: 375-383 (1976)

[10] Zhu D, Wen S Z. A full numerical solution for the thermoelastohydrodynamic problem in elliptical contact. ASME $J$ Tribol 106: 246-254 (1984) 
[11] Yang P R, Wen S Z. A generalized Reynolds equation based on non-Newtonian thermal elastohydrodynamic lubrication. ASME Trans J Tribol 112: 631-639 (1990)

[12] Hardy W B. Doubleday I. Boundary lubrication - the paraffin series. Proc R Soc Lond A 100: 550-563 (1921)

[13] Bowden F P, Tabor D. The Friction and Lubrication of Solid. Oxford (UK): Oxford University Press, 1954: 233-250.

[14] Adamson A W. The physical chemistry of Surfaces. In Interscience, Third Ed. New York, USA, 1976: 447-448.

[15] Kingsbury E P. Some aspects of the thermal of a boundary lubrication. J Appl Phys 29: 888-891 (1958)

[16] Cammera A. A theory of boundary lubrication. ASLE Trans 2: 195-198 (1959)

[17] Homola A M, Israelachvili J N. Fundamental studies in tribology: the transition from interfacial friction of undamaged molecularly smooth surfaces to "normal" friction with wear. In Proceedings of The 5th International Congress on Tribology, Finland, 1989: 28-49.

[18] Johnston G J, Wayte R, Spikes H A. The measurement and study of very thin lubricant films in concentrate contact. STLE Tribol Trans 34: 187-194 (1991)

[19] Luo J B, Wen S Z. Study on the mechanism and characteristics of thin film lubrication at nanometer scale. Science in China (Series A) 35: 1312-1322 (1996)

[20] Luo J B, Wen S Z, Li K Y. The effect of substrate energy on the film thickness at nanometer scale. Lubr Sci 10: 23-29 (1998)

[21] Luo J B, Huang P, Wen S Z. Characteristics of liquid lubricant films at the nano-scale. ASME Trans. ASME Trans $J$ Tribol 121: 872-878 (1999)

[22] Luo J B, Qian L M, Lui S, Wen S Z. The failure of liquid film at nano-scale. STLE Tribol Trans 42: 912-916 (1999)

[23] Tichy J A. Modeling of thin film lubrication. Tribol Trans 38(1): 108-118 (1995)

[24] Tichy J A. A surface layer model for thin film lubrication. Tribol Trans 38(3): 577-582 (1995)

[25] Hartl M, Krupka I, Poliscuk R, Liska M, Molimard J, Querry M, Vergne P. Thin film colorimetric interferometry. Tribol Trans 44(2): 270-276 (2001)

[26] Matsuoka H, Kato T. An ultrathin liquid film lubrication theory-Calculation method of solvation pressure and its application to the EHL problem. J Tribol 119(1): 217-226 (1997)

[27] Guangteng G, Spikes H A. Boundary film formation by lubricant base fluids. Tribol Trans 39(2): 448-454 (1996)

[28] Luo J B, Yian C N. Fuzzy view point in lubricating theory. Lubr Eng 4: 1-4 (1989)

[29] Gupta A, Sharma M M. Stability of thin aqueous films on solid surfaces. J Colloid Interf Sci 149: 392-424 (1991)

[30] Guangteng G, Spikes H A. The control of friction by molecular fractionation of base fluid mixtures at metal surfaces. Tribol Trans 40(3): 461-469 (1997)

[31] Harlt M, Krupka I, Liska M. Experimental study of boundary layers formation by thin film colorimetric interferometry. Science in China Series A-Mathematic Physics Astronomy 44: 412-417 (2001)

[32] Thompson P A, Grest G S, Robbins M O. Phase transitions and universal dynamics in confined films. Phys Rev Lett 68(23): 3448-3451 (1992)

[33] Hu Y Z, Wang H, Guo Y, Zheng L Q. Simulation of solidliquid transition in thin film lubrication. Lubrication and Sealing. 6: 16-20 (1995)

[34] Hu YZ, Wang H, Guo Y, Zheng L Q. Simulation of lubricant rheology in thin film lubrication, Part I: simulation of Poiseuille flow. Wear 196: 243-248 (1996)

[35] Hu Y Z, Wang H, Guo Y, Shen Z J, Zheng L Q. Simulation of lubricant rheology in thin film lubrication, Part II: simulation of Couette flow. Wear 196: 249 (1996)

[36] Bhushan B. Introduction to Tribology. John Wiley \& Sons, Ltd, 2013

[37] Wen S Z. Principle of Tribology. Beijing(China): Tsinghua University Press, 1991

[38] Luo J, Lu X, Wen S. Developments and unsolved problems in nano-lubrication. Progress in Natural Science 11(3): 173-183 (2001)

[39] Savio D, Fillot N, Vergne P. A molecular dynamics study of the transition from ultra-thin film lubrication toward local film breakdown. Tribol Lett 50: 207-220 (2013)

[40] $\mathrm{Hu}$ Y Z, Granick S. Microscopic study of thin film lubrication and its contributions to macroscopic tribology. Tribol Lett 5: 81-88 (1998)

[41] Hsu S, Ying C, Zhao F. The nature of friction: A critical assessment. Friction 2(1): 1-26 (2014)

[42] Dietzel D, Schwarz U D, Schirmeisen A. Nanotribological studies using nanoparticle manipulation: Principles and application to structural lubricity. Friction 2(2): 114-139 (2014)

[43] Israelachvili J N, McGuiggan P M, Homola A M Dynamic properties of molecularly thin liquid films. Science 240(4849): 189-191 (1988)

[44] Gee M L, McGuiggan P M, Israelachvili J N, Homola A M. Liquid to solidlike transitions of molecularly thin films under shear. J Chem Phys 93(3): 1895-1906 (1990)

[45] Tabor D F R S, Winterton R H S. The direct measurement of normal and retarded van der Waals forces. Proc $R$ Soc London A: Math Phys Eng Sci 312(1511): 435-450 (1969) 
[46] Bowden F P, Tabor D. Friction lubrication and wear- A survey of work during last decade. British Journal of Applied Physics 17(12): 1521-+ (1966)

[47] Israelachvili J N. The calculation of van der Waals dispersion forces between macroscopic bodies. Proc R Soc London A: Math Phys Eng Sci 331(1584): 39-55 (1972)

[48] Israelachvili J N, Tabor D. Measurement of van der Waals dispersion forces in the range 1.4 to $130 \mathrm{~nm}$. Nature 236(68): 106-106 (1972)

[49] Klein J, Kumacheva E. Confinement-induced phase-transitions in simple liquids. Science 269(5225): 816-819 (1995)

[50] Klein J, Kumacheva E. Simple liquids confined to molecularly thin layers. I. Confinement-induced liquid-to-solid phase transitions. J Chem Phys 108(16): 6996-7009 (1998)

[51] Granick S. Motions and relaxations of confined liquids. Science 253(5026): 1374-1379 (1991)

[52] Ma L, Luo J. Advances in thin film lubrication (TFL): From discovery to the aroused further researches. Science China Technological Sciences 58(10): 1609-1616 (2015)

[53] Cameron A, Gohar R. Theoretical and experimental studies of the oil film in lubricated point contact. Proc R Soc A 291: 520-535 (1966)

[54] Foord C A, Hammann W C, Cameron A. Evaluation of lubricants using optical elastohydrodynamics. ASLE Trans 11: 31-43 (1968)

[55] Wedeven L D, Foord C A, Westlake, F J, Cameron, A. Optical elastohydrodynamics. Proc Inst Mech Eng 184(1): 487-505 (1969-1970)

[56] Guangteng G, Spikes H A. Properties of ultrathin lubricating films using wedged spacer layer optical interferometry. In Interface Dynamics. In Proceedings of the 14th Leeds-Lyon Symposium on Tribology, Leeds, 1988: 275-279.

[57] Spikes H A. Thin films in elastohydrodynamic lubrication: the contribution of experiment. Proc Inst Mech Eng J: J Eng Tribol 213(15): 335-352 (1999)

[58] Cann P M, Spikes H A, Hutchinson J. The development of a spacer layer imaging method (SLIM) for mapping elastohydrodynamic contacts. STLE Tribol Trans 39: 915-921 (1996)

[59] Spikes H A, Cann P M. The development and application of the spacer layer imaging method for measuring lubricant film thickness. Proc Inst Mech Eng J: J Eng Tribol 215(J3): 261-277 (2001)

[60] Glovnea R P, Forrest A K, Olver A V, Spikes H A. Measurement of sub-nanometer lubricant films using ultrathin film interferometry. Tribol Lett 15: 217-230 (2003)

[61] Ma L, Zhang C. Discussion on the technique of relative optical interference intensity for the measurement of lubricant film thickness. Tribol Lett 36: 239-245 (2009)
[62] Luo J B, Shen M W, Shi B. Thin film lubrication and lubrication map. Chinese J Mechanical Engineering (in Chinese) 36(7): 15-21 (2000)

[63] Guo F, Wong P L. A multiple-beam intensity-based approach for thin lubricant film measurement in non-conformal contacts. Proc Inst Mech Eng J Eng Tribol 216: 281-291(2002)

[64] Guo F, Wong P L. A wide range measuring system for thin lubricating film: from nano to micro thickness. Tribol Lett 17: 521-531 (2004)

[65] Hartl M, Krupka I, Liska M. Differential colorimetry: Tool for evaluation of chromatic interference patterns. Optical Engineering 36: 2384-2391(1997)

[66] Hartl M, Krupka I, Poliscuk R, Liska M. An automatic system for real-time evaluation of EHD film thickness and shape based on the colorimetric inteferometry. Tribol Trans 42: 303-309 (1999)

[67] Cann P M. In-contact molecular spectroscopy of liquid lubricant films. MRS Bulletin 33(12): 1151-1158 (2008)

[68] Cann P M, Spikes H A. In-contact IR spectroscopy of hydrocarbon lubricants. Tribol Lett 19(4): 289-297 (2005)

[69] Bae S C, Lin Z, Granick S. Conjugated polymers confined and sheared: photoluminescence and absorption dichroism in a surface forces apparatus. Macromolecules 38: 9275-9279 (2005)

[70] Golan Y, Martin-Herranz A, Li Y, Safinya C R, Israelachvili J. Direct observation of shear-induced orientational phase coexistence in a lyotropic system using a modified X-ray surface forces apparatus. Phys Rev Lett 86(7): 1263-1266 (2001)

[71] Bae S C, Wong J, Kim M, Jiang S, Hong L, Granick S. Using light to study boundary lubrication: spectroscopic study of confined fluids. Philosophical Transactions of the Royal Society A-Mathematical Physical and Engineering Sciences 366(1869): 1443-1454 (2008)

[72] Bae S C, Lee H, Lin Z, Granick S. Chemical imaging in a surface forces apparatus: confocal Raman spectroscopy of confined poly (dimethylsiloxane). Langmuir 21(13): 56855688 (2005)

[73] Jiang S, Bae S C, Granick S. PDMS melts on mica studied by confocal Raman scattering. Langmuir 24(4): 1489-1494 (2008)

[74] Zhang S H, Liu Y H, Luo J B. In situ observation of the molecular ordering in the lubricating point contact area. J Appl Phys 116(1): 309-317 (2014)

[75] Zhang H Y, Zhang S H, Luo J B, Liu Y H, Qian S H, Liang, $\mathrm{F} \mathrm{H}$, Huang, Y L. Investigation of protein adsorption mechanism and biotribological properties at simulated stemcement interface. J Tribol-T ASME 135(3): 032301 (2013) 
[76] Chen C, Even M A, Chen Z. Detecting molecular-level chemical structure and group orientation of amphiphilic PEO-PPO-PEO copolymers at solution/air and solid/solution interfaces by SFG vibrational spectroscopy. Macromolecules 36(12): 4478-4484 (2003)

[77] Du Q, Freysz E, Shen Y R. Surface vibrational spectroscopic studies of hydrogen bonding and hydrophobicity. Science 264(5160): 826-828 (1994)

[78] Gao M, Ma L R, Gao Y, Guo D, Wang D S, Luo J B. Effect of metal ions on the morphology of silver nanocrystals. RSC Adv 4(41): 21571-21574 (2014)

[79] Gao M. Online research on molecular arrangement rule and micro mechanism of lubricant films. Ph.D Thesis. Beijing (China): Tsinghua University, 1994.

[80] Hamrock B J, Dowson D. Isothermal elastohydrodynamic lubrication of point contacts: Part III-Fully flooded results. J Lubr Technol 99(2): 264-275 (1977)

[81] Muraki M, Nakamura K. Film-forming properties and traction of non-functionalized polyalkylmethacrylate solutions under transition from elastohydrodynamic lubrication to thin-film lubrication. Proc Inst Mech Eng Part J-J Eng Tribol 224(J1): 55-63 (2010)

[82] Liang H, Guo D, Ma L R, Luo J B. The film forming behavior at high speeds under oil-air lubrication. Tribol Int 91: 6-13 (2015)

[83] Liang H, Guo D, Ma L R, Luo J B. Experimental investigation of centrifugal effects on lubricant replenishment in the starved regime at high speeds. Tribol Lett 59(1): 1-9 (2015)

[84] Zhu D. Elastohydrodynamic lubrication in extended parameter ranges-Part 1: Speed effect. Tribol Trans 45: 540-548 (2002)

[85] Zhu D. Elastohydrodynamic lubrication in extended parameter ranges-Part 2: Load effect. Tribol Trans 45: 549-555 (2002)

[86] Křupka I, Hartl M, Liška M. Thin lubricating films behaviour at very high contact pressure. Tribol Int 39(12): 1726-1731 (2006)

[87] Xiao H, Guo D, Liu S H, Lu X C, Luo J B. Experimental investigation of lubrication properties at high contact pressure. Tribol Lett 40(1): 85-97 (2010)

[88] Xiao H P. Research of lubrication properties in microgap under high contact pressure. Master Thesis. Beijing (China): Tsinghua University, 2011.

[89] Xiao H P, Guo D, Liu S H, Pan G, Lu, X C. Film thickness of ionic liquids under high contact pressures as a function of alkyl chain length. Tribol Lett 41(2): 471-477 (2011)

[90] Zhang S H. Experimental study on molecular arrangement of nanoscale lubricant films. Ph.D. Thesis. Beijing (China): Tsinghua University, 2014
[91] Luo J B, Shen M W, Wen S Z. Tribological properties of nanoliquid film under an external electric field. J Appl Phys 96(11): 6733-6738 (2004)

[92] Xie G X, Luo J B, Guo D, Nanoconfined ionic liquids under electric fields. Appl Phys Lett 96(4): 043112 (2010)

[93] Xie G X, Luo J B, Liu S H, Guo D, Zhang C H. Nanoconfined liquid aliphatic compounds under external electric fields: Roles of headgroup and alkyl chain length. Soft Matter 7(9): 4453-4460 (2011)

[94] Xie G X, Luo J B, Liu S H, Guo D, Zhang C. "Freezing" of nanoconfined fluids under an electric field. Langmuir 26(3): 1445-1448 (2010)

[95] Luo J B, He Y, Zhong M, Jin Z. Gas micro-bubble phenomenon in nanoscale liquid film under external electric field. Appl Phys Lett 89(1): 013104 (2006)

[96] Choi E M. Yoon Y H. Lee S. Kang H. Freezing transition of interfacial water at room temperature under electric fields. Phys Rev Lett 95(8): 085701 (2005)

[97] Zangi R. Mark A E. Electrofreezing of confined water. $J$ Chem Phys 120(15): 7123-7130 (2004)

[98] Capozza R, Vanossi A, Benassi A, Tosatti E. Squeezout phenomena and boundary layer formation of a model ionic liquid un(der confinement and charging. J Chem Phys 142(6): 064707/1-10 (2015)

[99] Pinilla C, Del Pópolo M G, Kohanoff J, Lynden-Bell R M. Polarization relaxation in an ionic liquid confined between electrified walls. J Phys Chem B 111(18): 4877-4884 (2007)

[100] Verma R, Sharma A, Kargupta K, Bhaumik J. Electric field induced instability and pattern formation in thin liquid films. Langmuir 21(8): 3710-3721 (2005)

[101] Bratko D Daub C D, Leung K, Luzar A. Effect of field direction on electrowetting in a nanopore. Journal of the American Chemical Society 129(9): 2504-2510 (2007)

[102] Zeng H, Tian Y, Anderson T H, Tirrell M, Israelachvili J N. New SFA techniques for studying surface forces and thin film patterns induced by electric fields. Langmuir 24(4): 1173-1182 (2008)

[103] Bratko D, Daub C D, Luzar A. Field-exposed water in a nanopore: liquid or vapour? Phys Chem Chem Phys 10(45): 6807-6813 (2008)

[104] Bou-Malham I, Bureau L. Nanoconfined ionic liquids: Effect of surface charges on flow and molecular layering. Soft Matter 6(17): 4062-4065 (2010)

[105] Srivastava S, Reddy P D S, Wang C, Bandyopadhyay D, Sharma A. Electric field induced microstructures in thin films on physicochemically heterogeneous and patterned substrates. J Chem Phys 132(17): 174703 (2010)

[106] Xie G, Luo J, Liu S, Zhang C, Lu X. Micro-bubble phenomenon in nanoscale water-based lubricating film 
induced by external electric field. Tribol Lett 29(3): 169-176 (2008)

[107] Xie G X, Luo J B, Liu S H, Guo D, Li G, Zhang C H. Effect of liquid properties on the growth and motion characteristics of micro-bubbles induced by electric fields in confined liquid films. J Phys D: Appl Phys 42(11): 115502 (2009)

[108] Xie G, Luo J, Liu S, Guo D, Zhang C. Bubble generation in a nanoconfined liquid film between dielectric-coated electrodes under alternating current electric fields. Appl Phys Lett 96(22): 223104 (2010)

[109] Ratoi M, Spikes H A. Lubricating properties of aqueous surfactant solutions. Tribol Trans 42(3): 479-486 (1999)

[110] Boschkova K, Kronberg B, Rutland M, Imae T. Study of thin surfactant films under shear using the tribological surface force apparatus. Tribol Int 34(12):815-822 (2001)

[111] Boschkova K, Feiler A, Kronberg B, Stalgren J J R. Adsorption and frictional properties of Gemini surfactants at solid surfaces. Langmuir 18: 7930-7935 (2002)

[112] Boschkova K, Kronberg B, Stalgren J J R, Persson K, Salagean M R. Lubrication in aqueous solutions using cationic surfactants-A study of static and dynamic forces. Langmuir 18:1680-1687 (2002)

[113] Liu S H. Studies on lubricating mechanisms and tribological properties of aqueous solutions. Ph.D. Thesis. Beijing (China): Tsinghua University, 2008.

[114] Lee S, Müller M, Ratoi-Salagean M, Vörös J, Pasche S, De Paul S M, Spikes H A, Textor M, Spencer N D. Boundary lubrication of oxide surfaces by poly (L-lysine)-g-poly (ethylene glycol)(PLL-g-PEG) in aqueous media. Tribol Lett 15(3): 231-239 (2003)

[115] Plaza S, Margielewskia L, Celichowskia G, Wesolowskia R W, Staneckaa R. Tribological performance of some polyoxyethylene dithiophosphate derivatives water solutions. Wear 249:1077-1089 (2001)

[116] Ma L R. Research on the lubricating characteristics and mechanisms of aqueous emulsions. Ph.D. Thesis. Beijing (China): Tsinghua University, 2010.

[117] Ma L R, Zhang C H, Luo J B. Investigation of the film formation mechanism of oil-in-water $(\mathrm{O} / \mathrm{W})$ emulsions. Soft Matter 7: 4207-4213 (2011)

[118] Ma L R, Zhang C H, Liu S H. Progress in experimental study of aqueous lubrication. Chinese Science Bulletin 57(17): 2062-2069 (2012)

[119] Ma L, Luo J, Zhang C, Liu S, Lu X, Guo D, Ma J B, Zhu T. Film forming characteristics of oil-in-water emulsion with super-low oil concentration. Colloids and Surfaces A: Physicochemical and Engineering Aspects 340(1): 70-76 (2009)
[120] Ma L, Xu X, Zhang C, Guo D, Luo J. Reemulsification effect on the film formation of $\mathrm{O} / \mathrm{W}$ emulsion. Journal of Colloid and Interface Science 417: 238-243 (2014)

[121] Ma L, Xu X, Zhang C, Luo J. Direct observation of the formation and destruction of the inverted continuous oil phase in the micro-outlet region achieved by the confined diluted O/W emulsion stream. Soft Matter 10(40): 7946-7951 (2014)

[122] Ma L, Zhang C, Luo J. Direct observation on the behaviour of emulsion droplets and formation of oil pool under point contact. Appl Phys Lett 101(24): 241603 (2012)

[123] Hirano M, Shinjo K. Atomistic locking and friction. Phys Rev B 41(17): 11837-11851 (1990)

[124] Shinjo K, Hirano M. Dynamics of friction: superlubric state. Surf Sci 283(1): 473-478 (1993)

[125] Li J J, Luo J B. Advancements in superlubricity. Science China Technological Sciences 56(12): 2877-2887 (2013)

[126] Tomizawa H, Fischer T E. Friction and wear of siliconnitride and silicon-carbide in water: Hydrodynamic lubrication at low sliding speed obtained by tribochemical wear. ASLE Trans 30(1): 41-46 (1987)

[127] Zhou F, Adachi K, Kato K. Sliding friction and wear property of a-C and a-CNx coatings against $\mathrm{SiC}$ balls in water. Thin Solid Films 514(1-2): 231-239 (2006)

[128] Xu J G, Kato K. Formation of tribochemical layer of ceramics sliding in water and its role for low friction. Wear 245(1-2): 61-75 (2000)

[129] Xu J G, Kato K, Hirayama T. The transition of wear mode during the running-in process of silicon nitride sliding in water. Wear 205(1-2): 55-63 (1997)

[130] Wang XL, Kato K, Adachi K, Aizawa K. Loads carrying capacity map for the surface texture design of $\mathrm{SiC}$ thrust bearing sliding in water. Tribol Int 36(3): 189-197 (2003)

[131] Klein J, Raviv U, Perkin S, Kampf N, Chai L, Giasson S. Fluidity of water and of hydrated ions confined between solid surfaces to molecularly thin films. J Phys-Condes Matter 16(45): 5437-5448 (2004)

[132] Klein J, Kumacheva E, Mahalu D, Perahia D, Fetters L J. Reduction of frictional forces between solid-surfaces bearing polymer brushes. Nature 370(6491): 634-636 (1994)

[133] Klein J. Hydration lubrication. Friction 1(1): 1-23 (2013)

[134] Kenausis G L, Voros J, Elbert D L, Huang N, Hofer R, Ruiz-Taylor L, Textor M, Hubbell J A, Spencer N D. Poly(L-lysine)-g-poly(ethylene glycol) layers on metal oxide surfaces: Attachment mechanism and effects of polymer architecture on resistance to protein adsorption. $J$ Phys Chem B 104(14): 3298-3309 (2000)

[135] Li J J, Zhang C H, Luo J B. Superlubricity behavior with phosphoric acid-water network induced by rubbing. 
Langmuir 27(15): 9413-9417 (2011)

[136] Ma Z Z, Zhang C H, Luo J B, Lu X C, Wen S Z. Superlubricity of a mixed aqueous solution. Chin Phys Lett 28: 056201 (2011)

[137] Li J J, Zhang C H, Sun L, Lu X, Luo J. Tribochemistry and superlubricity induced by hydrogen ions. Langmuir 28(45): 15816-15823 (2012)

[138] Li J J, Zhang C H, Ma L R, Liu Y, Luo J. Superlubricity achieved with mixtures of acids and glycerol. Langmuir 29(1): 271-275 (2013)

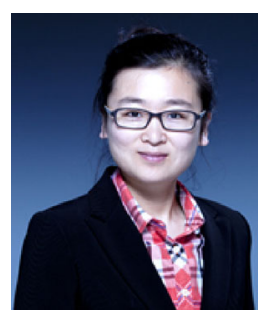

Liran MA. She received her BS degree from Tsinghua University in 2005, and received her Ph.D. degree from Tsinghua University in 2010. Following a postdoctoral period at the Weizmann Institute of Science in Israel, she is now working as an associate professor in State Key Laboratory of Tribology, Tsinghua University. Her

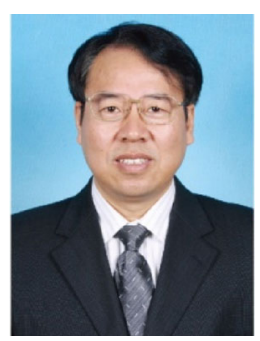

Jianbin LUO. He received his BEng degree from Northeastern University in 1982, and got his MEng degree from Xi'an University of Architecture and Technology in 1988. In 1994, he received his $\mathrm{PhD}$ degree from Tsinghua University and then joined the faculty of Tsinghua University. Prof. Jianbin Luo is an academician of the Chinese Academy of Sciences and a Yangtze River Scholar
[139] Li J J, Liu Y H, Luo J B, Liu P, Zhang C. Excellent lubricating behavior of Brasenia Schreberi Mucilage. Langmuir 28(20): 7797-7802 (2012)

[140] Gao M, Ma L, Luo J. Effect of alkyl chain length on the orientational behavior of liquid crystals nano-film. Tribol Lett 62(2): 1-7 (2016)

[141] Gao M, Online Research on Molecular Arrangment Rule and Micro Mechanism of Lubricant Films, Ph.D. Thesis, Beijing (China): Tsinghua University, 2016.

interests in tribology have ranged from aqueous lubrication and hydration lubrication to the liquid/solid interface properties. She has published over 40 papers. Her work has been cited 200 times. Her honors include the Hinwin Doctoral Dissertation Award (2011), the Maple Leaf Award for Outstanding Young Tribologists (2015), and Chang Jiang Scholars Program-Young Professor Award (2015).

Distinguished Professor of Tsinghua University, Beijing, China. He was awarded the STLE International Award (2013), the Chinese National Technology Progress Prize (2008), the Chinese National Natural Science Prize (2001), and the Chinese National Invention Prize (1996). Prof. Luo has been engaged in the research of thin film lubrication and tribology in nanomanufacturing. He was invited as a keynote or plenary speaker for 20 times on the international conferences. 